\begin{tabular}{|c|c|c|c|c|c|}
\hline MUNIBE Antropologia-Arkeologia & $n^{\circ} 68$ & $5-31$ & DONOSTIA & 2017 & ISSN 1132-2217 • elSSN 2172-4555 \\
\hline
\end{tabular}

\title{
El tecno-complejo del Embalse de Urrúnaga (Álava). Nuevas aportaciones al conocimiento de las sociedades del Paleolítico inferior en el norte de la Península Ibérica
}

\author{
The techno-complex of Urrúnaga Dam (Álava). New contribution to the \\ knowledge of Lower Palaeolithic societies in the northern Iberian Peninsula
}

PALABRAS CLAVES: Achelense superior/final. Industria lítica. Tipología. Tecnología. Materias primas. Conjunto de superficie.

GAKO-HITZAK: Goiko/amaierako Acheularra. Industria litikoa. Tipologia. Teknologia. Lehengaiak. Gainazal multzoa.

KEY WORDS: Upper/final Acheulian. Lithic industry. Lithic typology. Lithic technology. Lithic raw materials. Surface archaeological assemblage.

\section{Javier FERNÁNDEZ-ERASO(1), Maite GARCÍA-ROJAS(2), Aitor SÁNCHEZ(1), Alejandro PRIETO(1), Aitor CALVO(1), Eder DOMÍNGUEZ-BALLESTEROS ${ }^{(1)}$, Antonio TARRIÑO( ${ }^{(3)}$, Joseba LÓPEZ-DE-OCÁRIZ(1), Marcel BRADTMÖLLER ${ }^{(4)}$ y Tomás URIGOITIA(5)}

\section{RESUMEN}

En este trabajo se presenta una nueva colección lítica adscrita al Paleolítico inferior recuperada en el embalse de Urrúnaga (Álava, País Vasco, España). Consta de 70 artefactos que han sido estudiados conforme a los parámetros de la Tipología Analítica a partir de las estructuras de análisis; Petrológica, Modal-Morfológica, Tecnológica y Tipométrica. A partir de este estudio integral e interdisciplinar se han podido comprender los procesos de captación de materias primas y las diferentes dinámicas de talla a la hora de elaborar los diferentes artefactos. De este modo, el tecno-complejo aquí presentado, supone un nuevo aporte al conocimiento de las comunidades inferopaleoliticas en un territorio donde escasean las evidencias arqueológicas de este periodo cronológico. Además pone de manifiesto la importancia del emplazamiento en el que se sitúa el embalse como un lugar de paso obligado para la comunicación entre el interior meseteño, valle del Ebro y la costa.

\begin{abstract}
LABURPENA
Lan honetan, Urrunagako urtegian (Araba) berreskuratutako Behe Paleolitikoko bilduma litiko berria aurkeztuko dugu. Azterketa-egituretatik abiatuta, tipologia analitikoaren parametroen arabera ikertutako 70 tresna dira: petrologikoa, moda-morfologikoa, teknologikoa eta tipometrikoa. Diziplina ugari biltzen dituen azterketa integral horretatik abiatuta, tresna ugariak egiteko garaian erabilitako zizelkatze-dinamika ugariak eta lehengaiak eskuratzeko prozesuak ulertu ahal izan ditugu. Hala, hemen aurkeztutako tekno-konplexuak Behe Paleolitikoko komunitateen ezagutzara egindako ekarpen berria ekarri du. Horrekin lotuta, aipatu beharreko da lurralde horretan guti direla aldi kronologiko horretako ebidentzia arkeologikoak. Gainera, urtegiaren kokapenak duen garrantzia agerian geratu da. Izan ere, barneko mesetaren, Ebro haranaren eta kostaldearen arteko komunikaziorako derrigorrezko pasagunea da.
\end{abstract}

\section{ABSTRACT}

This paper presents a new Lower Palaeolithic lithic assemblage recovered from the Urrúnaga reservoir (Álava, Basque Country, Spain). The collection consists of 70 artefacts, which have been analysed according to the petrological, modal-morphological (retouching structures), technological and metrical structures following the Analytical Typology approach. Even small by artefact number, this assemblage can contribute, through a comprehensive and interdisciplinary methodology, to a better understanding of raw material acquisition dynamics, as well as knapping and retouching techniques carried out by Lower Palaeolithic societies.

Concerning the raw material acquisition, the massive use of shale suggests the dominance of local procurement patterns. However, the systematic use of distinct siliceous cemented shale reflects selective strategies for alluvial deposits. We propose, that this selection is based on two raw material criteria: knapping properties, derived from the fine and homogenous grain-size and the hardness due to its silica cement composition.

The further procession of this pebbles suggests two different techniques. The first one describes an uni- and bifacial exploitation, producing side scrapers, scrapers and denticulates. The second one is based on centripetal cores. Blanks and cores were also modified, using similar

\footnotetext{
(1) Departamento de Geografía, Prehistoria y Arqueología. Área de Prehistoria. Universidad del País Vasco/Euskal Herriko Unibertsitatea (UPV/ EHU). (javier.fernandeze@ehu.eus ORCID: 0000-0002-9860-2610), (maite.garciar@ehu.eus), (aitor.sanchez|@ehu.eus ORCID: 0000-00026538-3095), (alejandro.prieto@ehu.eus ORCID: 0000-0002-3853-525X) (aitor.calvo@ehu.eus ORCID: 0000-0002-3753-8731), (eder.dominguez@ehu.eus ORCID: 0000-0002-7338-8232) (jlopezdocariz@gmail.com).

(2) Università degli Studi di Ferrara. Dipartimento di Studi Umanistici. Sezione di Scienze Preistoriche e Antropologiche. Departamento de Geografía, Prehistoria y Arqueología. Área de Prehistoria. Universidad del País Vasco/Euskal Herriko Unibertsitatea (UPV/EHU) (maite.garciar@ ehu.eus/grcmta@unife.it).

(3) Centro Nacional de Investigación sobre la Evolución Humana (CENIEH) (antonio.tarrinno@cenieh.es).

(4) Institute for Prehistoric Archaeology, University of Erlangen (marcel.bradtmoeller@ehu.eus).

(5) Instituto Alavés de Arqueología (IAA) (turigoitia@hotmail.com).
} 
retouching techniques as for the artefacts directly made on pebbles. The metrical dataset derived from this analysis shows that artefacts on pebbles and cores have similar dimensions, nevertheless, retouched and non-retouched flakes have irregular size distribution.

This lithic techno-complex provides new information about Lower Palaeolithic groups within a region, where the archaeological evidences for this period are scarce. In addition, this paper highlights the importance of this reservoir area, located as a mandatory crossroad between the North-Iberian plateau, the Ebro valley and the Cantabrian coastal region.

\section{INTRODUCCIÓN}

Las industrias líticas talladas, de cronología inferopaleolítica, no suponen una novedad en la Prehistoria del Territorio Histórico de Álava. Hallazgos descontextualizados han sido efectuados desde la primera mitad del siglo XX. Así, a las citas de H. Breuil en torno al descubrimiento del bifaz de Murua, en 1919 (Baldeón, 1974:39), hay que añadir la del bifaz de Aitzabal, descrito por J. M. Barandiaran entre 1934 y 1935 (Barandiarán, 1953). En fechas más recientes, destaca el de un hendedor en Peñacerrada encontrado por J. A. Madinabeitia en 1978 (Baldeón, 1978a), o el de los conjuntos de industrias talladas sobre cuarcita que fueron localizadas en Mendiguri (Laño, Treviño) y Ondabia (Pagoeta, Peñacerrada) y publicados por A. Sáenz de Buruaga, T. Urigoitia y J. A. Madinabeitia (1994).

El sistema de embalses del río Zadorra, Urrúnaga y Ullibarri-Gamboa, construido entre 1947 y 1957, ha dejado al descubierto importantes conjuntos de industria lítica tallada y pulimentada, cerámica y otros elementos de cronologías que abarcan desde el Paleolítico inferior hasta etapas de época contemporánea (Baldeón, 1978b; Sáenz de Buruaga y Urigoitia, 1986; Sáenz de Buruaga et al., 1988/1989, 1992; Ormazabal et al., 1994; Fernández Eraso et al., 1995; Fernández Eraso et al., 2003; Férnandez Eraso et al., 2004, 2005; Fernández Eraso, 2006; Fernández Eraso et al., 2012; Sánchez, 2012; Sánchez et al., 2013). En 1985 se produjo el descubrimiento de tres piezas excepcionales en los sitios de Kargaleku y Belaustegui (Sáenz de Buruaga y Urigoitia, 1986); se trataba de tres cantos tallados bidireccionalmente fabricados sobre lutita. Este hallazgo supuso la intensificación de las prospecciones en las orillas de los embalses aprovechando los ciclos de estiaje. El constante movimiento de las aguas ha propiciado la erosión de las tierras que conforman el vaso y el depósito de los materiales más pesados que las aguas no pueden arrastrar. La labor de prospección realizada a partir 1985 dio lugar a la primera publicación de un conjunto extenso en la cual se ensayaba, además, una nueva metodología de estudio basada en los criterios emanados de la Tipología Analítica (Sáenz de Buruaga et al., 1989). Desde esa fecha se han ido realizando nuevos descubrimientos que han visto la luz en un trabajo más reciente (Fernández Eraso, 2006), al que hay que añadir el conjunto que en este artículo se presenta.

Este estudio trata de dotar de contexto y contenido a las industrias líticas inferopaleolíticas recuperadas en los últimos años en las orillas del embalse de Urrúnaga, pues suponen uno de los pocos vestigios que nos acercan al conocimiento de estas sociedades en la zona. Para ello, exponemos la información obtenida del análisis de su contexto geográfico, geológico y deposicional, de la lectura de las dinámicas de aprovisionamiento, gestión, técnica y morfología de los artefactos recuperados y finalmente, su relación con yacimientos y hallazgos arqueológicos similares en la zona. Estas nuevas evidencias, y la información de las mismas, vienen a poner de manifiesto la importancia del emplazamiento en el que se sitúa el embalse, lugar de paso obligado entre el interior y la costa hasta la actualidad.

\section{MARCO GEOGRÁFICO Y GEOLÓGICO}

El embalse de Urrúnaga se ubica en el municipio de Legutiano al norte de la ciudad de Vitoria-Gasteiz, en zona limítrofe entre los territorios de Álava y Bizkaia (Fig.1). La mayor parte del embalse pertenece al municipio de Legutiano aunque parte de la presa se encuentra en el término municipal de Otxandio. Se sitúa en la zona central del dominio geográfico de los Montes Vascos, entre la Sierra del Gorbea al Oeste, la Sierra del Amboto al Norte y la Sierra del Aratz-Aitzkorri al Este. AI Sur, se abre la Llanada Alavesa y por tanto el dominio geográfico del Valle del Ebro. Este embalse recibe las aguas de multitud de ríos provenientes de las serranías que le rodean, siendo el río de Santa Engracia su principal deudor. Las aguas del embalse, bajan hasta el río Zadorra y tras atravesar la llanada alavesa, vierte sus aguas al río Ebro.

Geológicamente, el embalse se encuentra sobre una secuencia normal homoclinal que buza hacia el sur constituida por materiales sedimentarios cretácicos que abarcan desde el Albiense medio (Cretácico inferior) hasta el Cenomaniense superior (Cretácico superior) (Fig.2). Los estratos de la secuencia estratigráfica no contiene grandes discontinuidades, solo está afectada ligeramente por una falla en su base. En la zona Norte, donde el embalse recibe las aguas del río Urkiola, se asienta sobre areniscas blancas, limolitas y niveles de arcillas arenosas del Albiense medio y superior. Según avanzamos al Sur, los materiales del sustrato van pasando a calizas, en la base de la secuencia, y areniscas calcáreas y arcillas arenosas con nódulos en la parte superior del Cenomaniense inferior. La zona sur del embalse, hasta donde se ubica la presa, se sitúa sobre una alternancia regular de calizas arcillosas y margas del Cenomaniense medio y superior (Fig.2).

La propia acción erosiva ha generado un perfil en el que se aprecia la secuencia sedimentaria natural (Fig.3). En él se puede identificar un nivel de margas meteorizadas que se apoya sobre un sustrato margoso. Superpuesto a este frente de alteración descansa un nivel de cantos de lutita y arenisca de origen natural y 


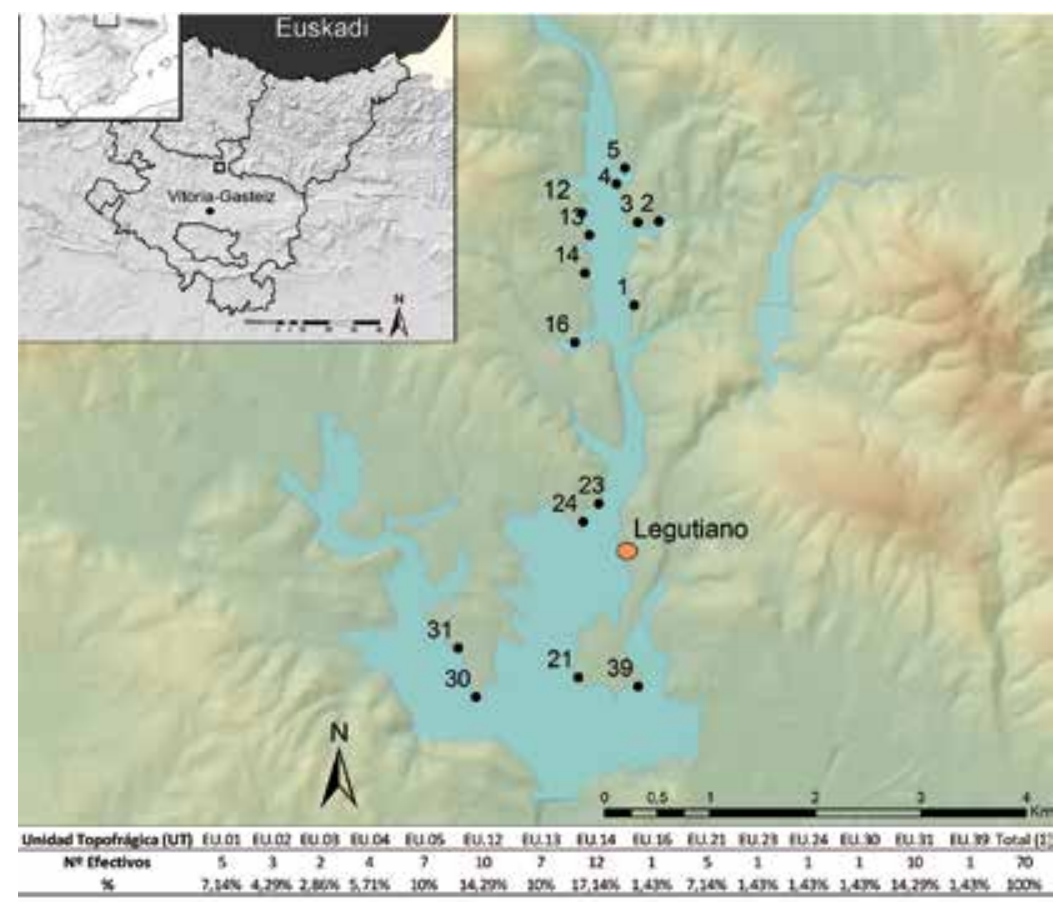

Fig. 1. Localización geográfica y distribución de los materiales analizados (Modelo digital del terreno obtenido de (C) Instituto Geográfico Nacional) y tabla con la distribución de los efectivos por Unidades Topográficas, (EU es igual a Embalse de Urrúnaga) / Map from the area of study based on Digital Elevation Model obtained by the (C) Instituto Geográfico Nacional, showing the location (EU) of the archaeological findings. Also, table with the quantity of the archaeological pieces which correspond in each location.

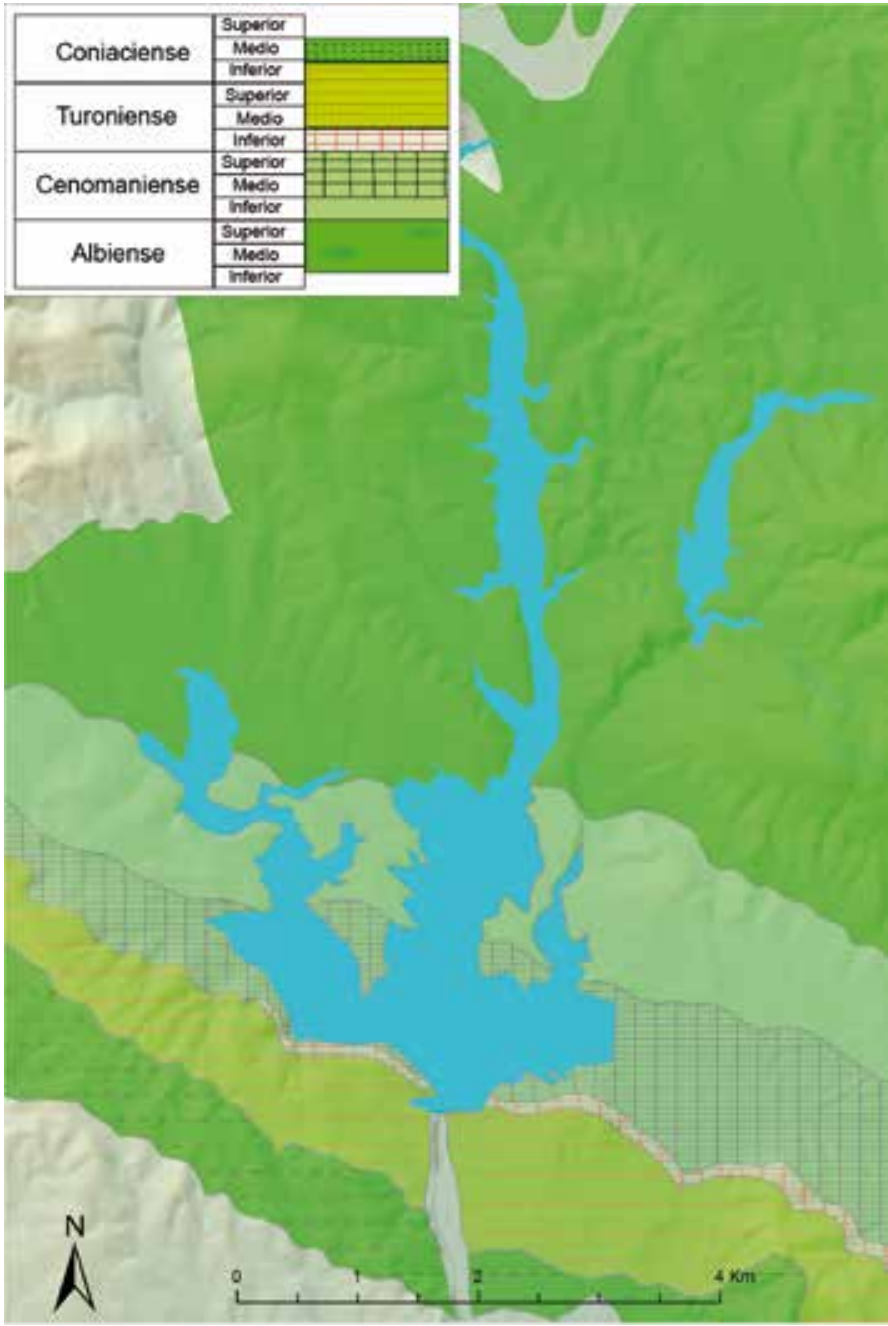

Fig. 2. Caracterización geológica del área de estudio (IGME 1991 , 1991b) / General geological characterization map and schematic geologic section modified from IGME (1991, 199b). 


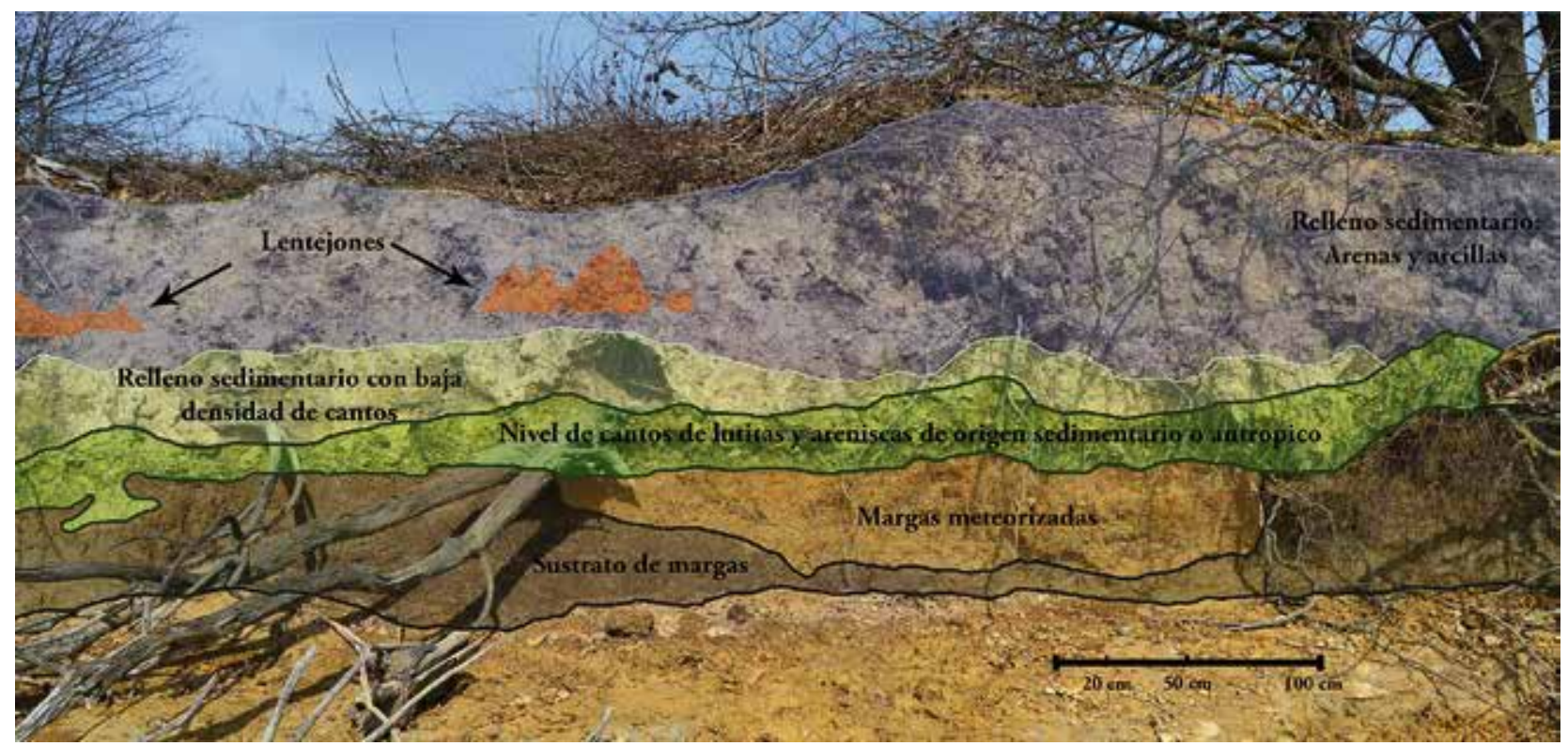

Fig. 3. Secuencia sedimentaria del perfil natural / Natural sedimentary sequence section in Urrunaga DAM.

posiblemente el que ha servido de fuente de captación de las materias primas empleadas para elaborar los materiales que analizamos en este trabajo. En la parte superior, se distingue un relleno sedimentario con baja densidad de cantos y sobre él otro relleno de arenas y arcillas de base erosiva muy irregular que presenta lentejones de diferente coloración.

Entre el perfil y la orilla se observa una zonación como consecuencia de la propia acción del agua (Fig.4). El lugar más alejado de la orilla se caracteriza

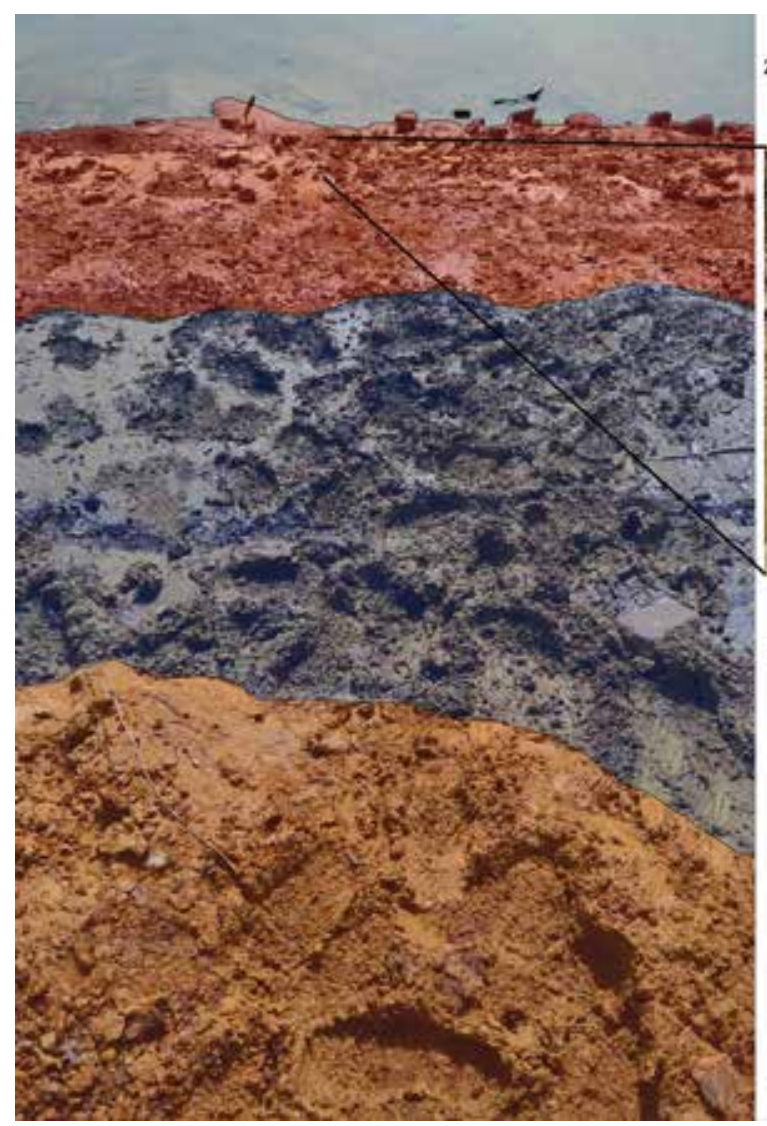

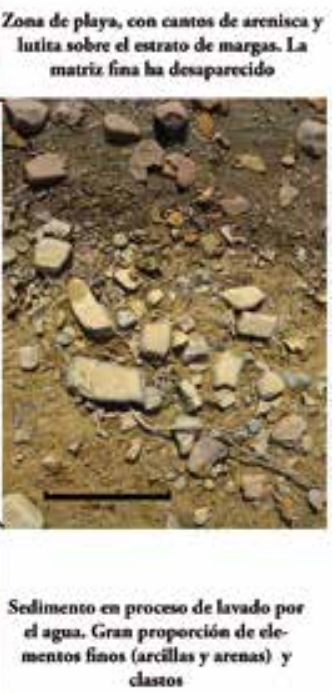

Sedimento proveniente del perfil conionado por d pantune y azgentes metcoralógicoss Ardillas, arenas $y$ dastos
Fig. 4. Zonación sedimentaria entre el perfil natural y la orilla del embalse / Washing process of natural section of sediment eroded by the reservoir. 
por un depósito de arenas, arcillas y clastos que provienen de la degradación del perfil por parte del embalse y de los agentes meteorológicos. En la zona intermedia se aprecian sedimentos en proceso de lavado con una gran proporción de elementos finos (arenas y arcillas) y clastos. Por último, la zona de la orilla se compone por un depósito de cantos de arenisca y lutita sobre el estrato de margas sin matriz fina.

\section{METODOLOGÍA DE ESTUDIO}

Cómo viene siendo habitual en el estudio de los conjuntos líticos de superficie del oriente alavés, hemos utilizado los parámetros establecidos por la Tipología Analítica para su descripción. El análisis tecno-tipológico de los útiles ${ }^{1}$ sobre canto y núcleos lo hemos realizado según la propuesta de Sáenz de Buruaga et al. (1988-1989). Para los materiales retocados hemos empleado la Grillé de 1986 (Laplace, 1987; Fernández Eraso y García-Rojas, 2013), y para los Productos Brutos de Talla (PBT) la metodología desarrollada por García-Rojas (2010). Además, hemos tomado las medidas de todos los elementos del conjunto lítico; los útiles sobre canto y núcleos han sido medidos a partir de su longitud mayor, mientras que los materiales retocados y los Productos Brutos de Talla a través de su eje tecnológico y utilizando, para estos últimos, la propuesta de Bagolini (1968) y su posterior simplificación realizada por Fernández Eraso (2005). Por último, hemos identificado la materia prima lítica. El método de trabajo empleado ha sido el análisis no destructivo y formal de las litologías. Al tratarse de rocas detríticas (lutitas y areniscas) hemos descrito la granulometría, matriz y tipo de cementación empleando una lupa binocular convencional con aumentos comprendidos entre 10x y 20x.

\section{DISTRIBUCIÓN DE LOS MATERIALES}

El material recuperado se encuentra repartido en diferentes unidades topográficas (Fig.1). A continuación realizaremos una descripción de los caracteres morfo-técnicos más relevantes. El conjunto aquí estudiado carece de contexto estratigráfico; aun así, muestran coherencia morfo-técnica lo que nos permite abordar el análisis de manera conjunta. De este modo, y como primera aproximación, agrupamos todos los efectivos en tres categorías mayores: núcleos, Productos Brutos de Talla (PBT) y artefactos tallados y/o retocados (tabla I).

Desde un punto de vista cuantitativo, las categorías dominantes son los productos tallados y/o retocados junto a los núcleos, frente a una reducida presencia de Pro- ductos Brutos de Talla. Esta ordenación nos indica una sobrerrepresentación, respecto a la media, de elementos masivos con relación a los Productos Brutos de Talla, tales como lascas, láminas o lascas laminares (Fig.5).

\begin{tabular}{|c|c|c|c|c|}
\hline Categorías & $\mathrm{N}^{\circ}$ Efectivos & $\%$ & Fr. & Fr.-m. \\
\hline Núcleos & 25 & $35,71 \%$ & 0,357 & 0,024 \\
\hline PBT & 13 & $18,57 \%$ & 0,186 & $-0,148$ \\
\hline $\begin{array}{l}\text { Tallado/ } \\
\text { Retocado }\end{array}$ & 32 & $18,57 \%$ & 0,457 & 0,124 \\
\hline 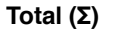 & 70 & $100,00 \%$ & 1 & \\
\hline m. & 23,333 & & 0,333 & \\
\hline
\end{tabular}

Tabla 1: Reparto de los efectivos atendiendo a las categorías mayores de análisis. (PBT = Productos Brutos de Talla) / Distribution of elements according to the main analysis categories. (PBT = Non-retouched/Non-knapped blank).

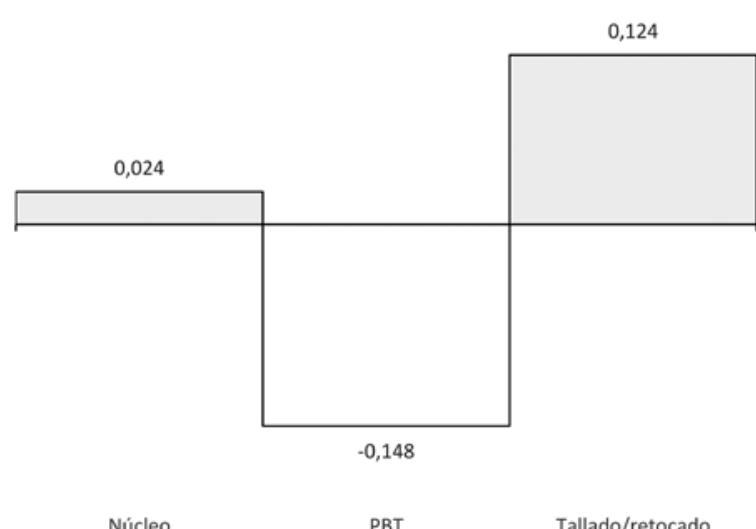

Fig. 5. Representación de los efectivos a partir de las frecuencias relativas de cada categoría respecto a la media / Chart representation of each element (Core, or non-knapped/non-retouched blank, or knapped/retouched blank/pebble) based on the relative frequencies of each category in relation to the mean.

\section{LOS DATOS Y RESULTADOS}

Para le exposición de los datos mantendremos las estructuras de análisis establecidas por la Tipología Analítica. De este modo, en los siguientes subapartados se indican de manera individualizada la información referente a las materias primas identificadas (estructura Petrológica). La descripción de los instrumentos configurados a partir de la talla y/o retoque (estructura Modal y Morfológica). En este sentido cabe señalar que los diferentes morfo-temas que configuran los artefactos tallados y retocados pueden ser asimilados a la denominación contenida en la Grille de 1986 ya que, desde un punto de vista técnico y morfológico pueden ser definidos mediante los criterios tipológicos con base en el modo y articulación de su retoque, in-

\footnotetext{
${ }^{1}$ En este trabajo el término útil se emplea para hacer referencia a todos los artefactos que presentan unas características morfo-técnicas que pueden ser descritas y definidas desde los parámetros tipológicos expuestos por la Tipología Analítica con relación a su retoque, indistintamente cual sea su soporte / In this text, the denomination of tool includes all the artifacts showing morpho-technical characteristics that can be described according to parameters for retouch defined by Analytical Typology, independently of their blank.
} 
distintamente del soporte empleado, ya sea un producto bruto de talla o un canto.

El análisis que nos facilita la identificación de las diferentes técnicas de talla empleadas a la hora de conformar los artefactos analizados (estructura Tecnológica). Tales como el carácter unifacial o bifacial en la dirección de la talla, delineación de los diferentes filos o articulación de los negativos de los Productos Brutos de Talla, y la dinámica de reducción de los propios núcleos. Por último, se analiza las dimensiones propias de cada grupo tipológico (estructura Tipométrica).

\subsection{Estructura Petrológica}

Hemos analizado la totalidad del conjunto lítico recuperado (70 evidencias). Dentro de la gran homogeneidad del conjunto se ha intentado reflejar la variabilidad de las diferentes materias primas identificando los siguientes tipos petrológicos:

1. Lutita: Roca sedimentaria detrítica de grano fino a muy fino, tamaño limo-arcilla, cuyos granos no superan los 0,0625 milímetros. La presencia de sílice en el cemento de todas las lutitas que componen el conjunto arqueológico es claro. No existen por tanto lutitas ferruginosas o calcáreas, frecuentes en el contexto del embalse de Urrúnaga. Las piezas que componen la colección están generalmente alteradas por procesos postdeposicionales y la afección de óxidos de manganeso o de hierro. El 97\% de las piezas del conjunto lítico son estas lutitas silíceas.

2. Arenisca: Roca sedimentaria detrítica compuesta principalmente por granos de cuarzo de tamaño que varía de fino a medio, comprendido entre los $0,0625 \mathrm{~mm}$ hasta $0,5 \mathrm{~mm}$. Las dos areniscas existentes en este conjunto carecen de elementos que marquen evidencias de estrés metamórfico y son muy homogéneas respecto a su clasificación.

3. Sílex: La única pieza del conjunto realizada sobre esta roca silícea diagenética está muy alterada, impidiendo observar características texturales que la caracterizan por lo que no se le puede asignar el origen de alguno de los tipos definidos en la región (Tarriño, 2006).

A nivel general, las materias primas de este conjunto lítico se comportan de forma muy homogénea y se componen principalmente por lutitas de cemento silíceo (97\%), quedando la arenisca (2\%) y sílex (1\%) como elementos residuales. A excepción del sílex, tanto la lutita como las areniscas son frecuentes en las inmediaciones en depósitos de cantos que, así mismo, tienen una forma y tamaño variable.

\subsection{Estructura Modal y Morfológica}

Artefactos manufacturados que lleguen a confirmar útiles identificables, desde un punto de vista tipológico, se han podido estudiar un total de treinta y dos. De ellos la mitad están fabricados sobre Productos Brutos de TaIla, bien sean lascas, láminas o lascas-laminares y, la otra mitad restante se conforma sobre soporte de cantos, generalmente, carenados. Dentro de este último apartado se reúnen una serie de artefactos, de formato grueso, que se identifican con hendedores, pero también útiles de menores dimensiones que son claramente equiparables con otros que, tradicionalmente, se han adscrito a soportes correspondientes a Productos Brutos de Talla. Se trata de artefactos cuyos retoques se disponen de manera similar a como la hacen sus homólogos sobre soporte bruto de talla (raederas, raspadores, puntas o denticulados) y que pueden ser asimilados a ellos, manteniendo su diferenciación en cuanto al soporte.

En resumen, los artefactos estudiados en el presente trabajo se agrupan de la siguiente manera, atendiendo al soporte sobre el que están fabricados, en cantos y Productos Brutos de Talla.

\subsubsection{Artefactos sobre canto}

Se recuperaron dieciséis elementos distribuidos de la manera siguiente, atendiendo a los grupos tipológicos con los que se asocian:

Hendedores: Se ha recuperado un solo individuo que ofrece un filo obtenido mediante golpes alternos en ambas caras y se localiza en el extremo distal del canto (Fig.6.1).

Raspadores: De este grupo tipológico se recuperaron dos artefactos pertenecientes al tipo raspador frontal con retoque lateral (G12). Se trabajó mediante retoque Simple, profundo en una de las zonas polares del canto y muestra una composición latero-transversal entre el retoque lateral y el frente de raspador (Fig.7.1).

Raederas: Este grupo reúne un total de ocho efectivos.

Las raederas laterales (R1) están representadas mediante tres individuos. Se desarrollan sobre cantos carenados y ofrecen retoques Simples, unifaciales, profundos o muy profundos en uno de los laterales.

Raederas latero-transversales (R3) se han identificado cinco (Fig.7.2 y 8.2). Muestran retoques Simples, profundos o muy profundos, cuatro de ellos presentan el retoque en el lateral izquierdo y continua en su parte transversal distal y, en el último, transversal distal con lateral derecho.

Puntas: De este grupo se han clasificado y estudiado dos ejemplares correspondientes al tipo primario (P1) punta simple (Fig.9.2). Todos están fabricados sobre cantos carenados que conservan amplias zonas de córtex.

Denticulados: El grupo está representado por dos raederas denticuladas (D3) y una punta (D4). Raederas denticuladas (D3) se han contabilizado dos que presentan córtex y están configuradas mediante retoques simples, bidireccionales en un caso, y bifaciales, en el otro (Fig.8.1 y 9.1). 
Punta denticulada (D4) solamente se recuperó un ejemplar que, además, conserva córtex. Está conformado por retoque Simple profundo, localizado en el ex- tremo distal del canto, siendo lateral, izquierdo, distal, bifacial opuesto a Simple alterno.
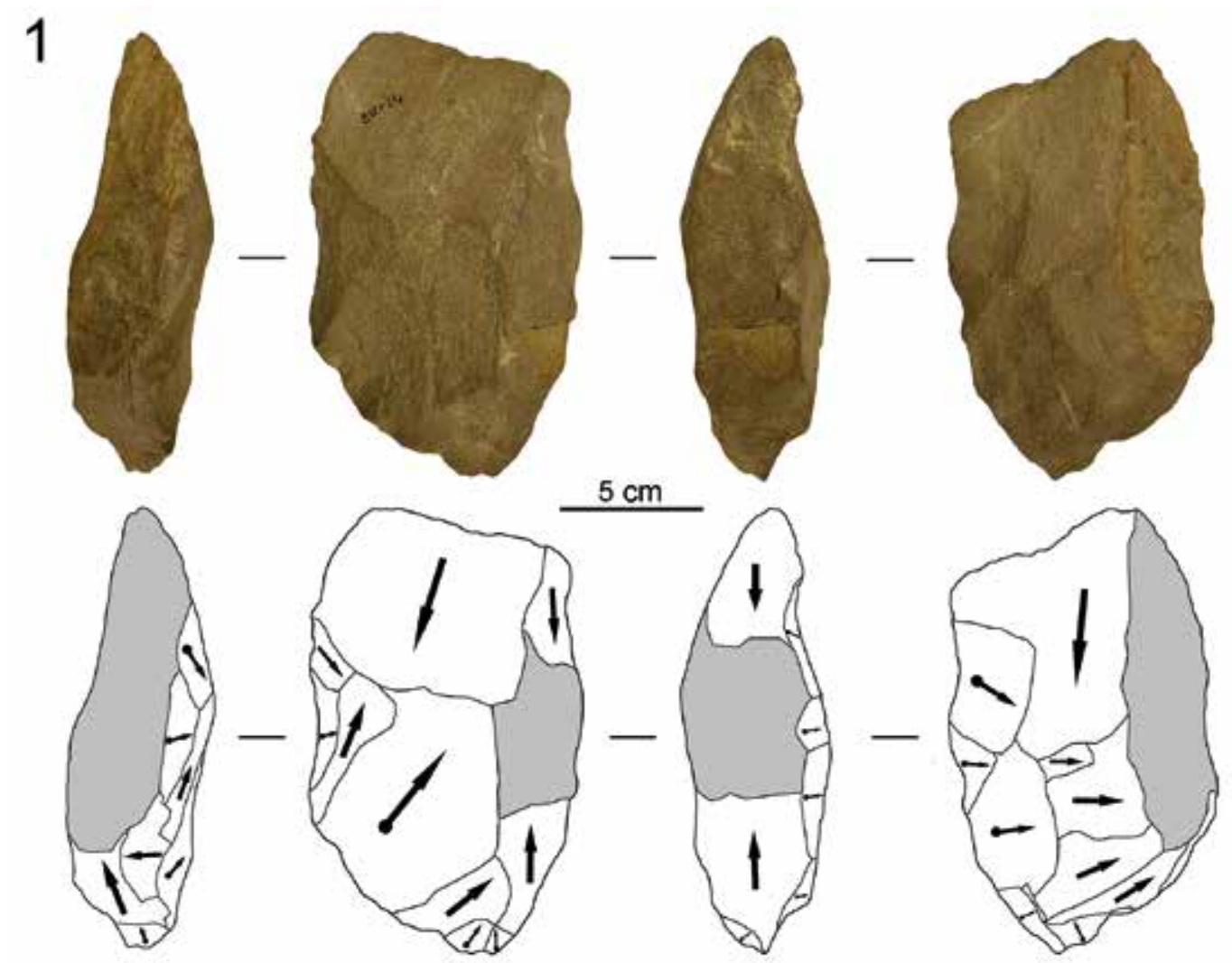

2
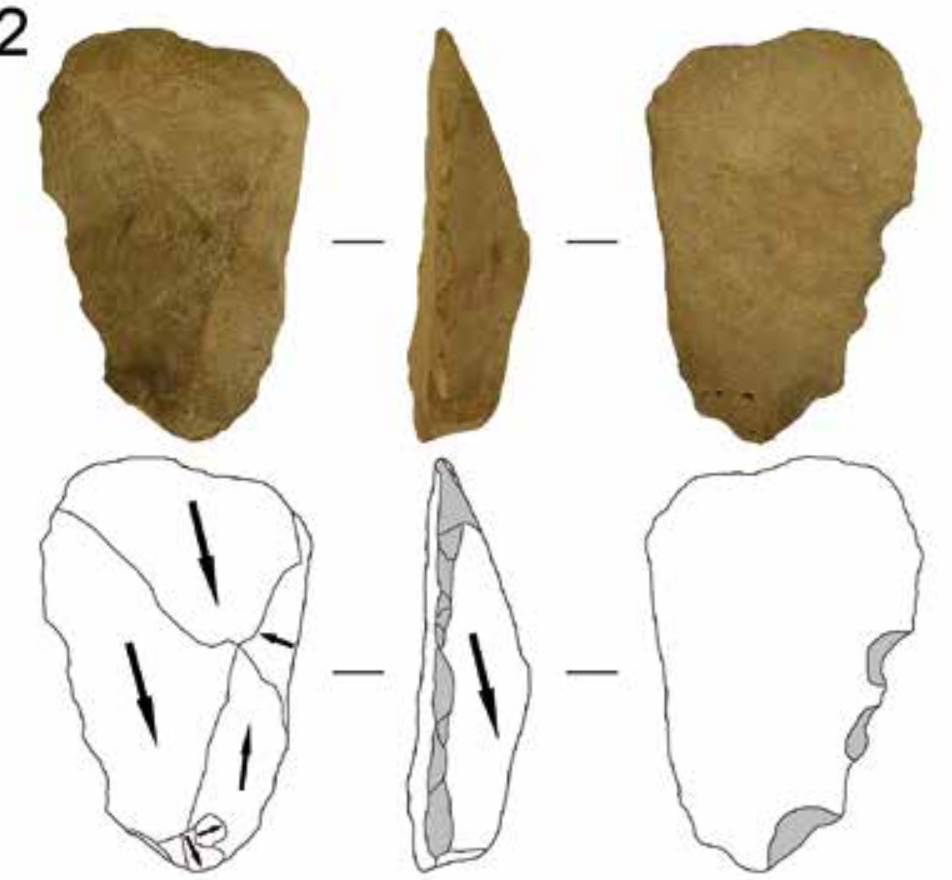

Fig. 6. Hendedores. 1) Hendedor sobre canto. 2) Hendedor sobre gran lasca. En el caso del hendedor $n^{\circ} 1$, las zonas resaltadas en gris se corresponden con planos naturales de la materia prima. En el caso del n², éstas se refieren a pseudoretoques recientes / Cleavers. 1) Cleaver on pebble. Shaded area represent cortical remains. 2) Cleaver on big flake. Shaded area represent pseudo-retouched area derived by recent action. 

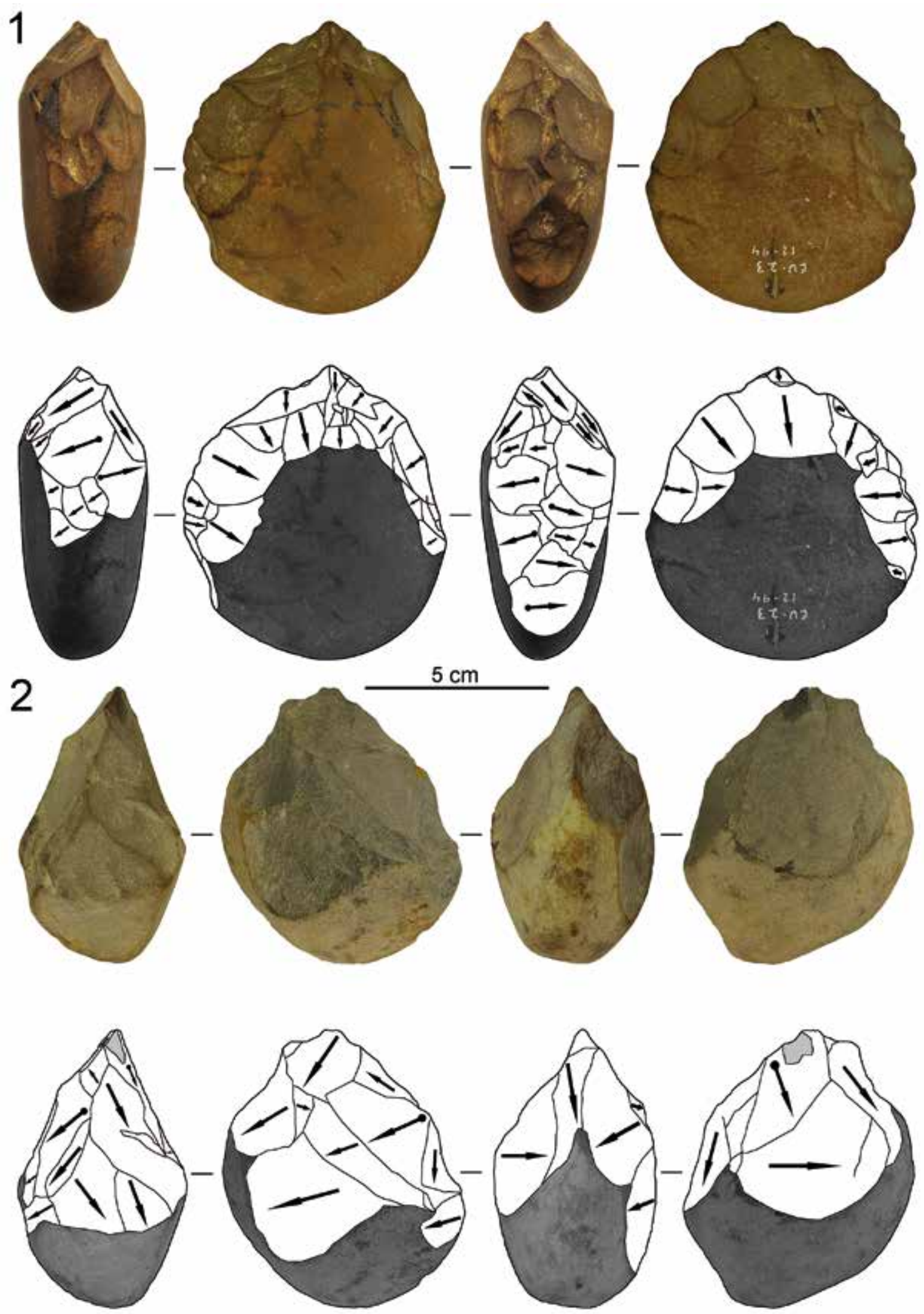

Fig. 7. Artefactos sobre canto. 1) Canto tallado bidireccional (Raspador frontal con retoque bidireccional). 2) Canto tallado bidireccional (raedera latero-transversal). El negativo resaltado en gris se trata de una alteración reciente / Knapped pebbles. 1) Biderectional knapped pebble (bidirectional scraper). 2. Bidirectional knapped pebble (lateral-transversal side scraper). Cortical area are shaded 

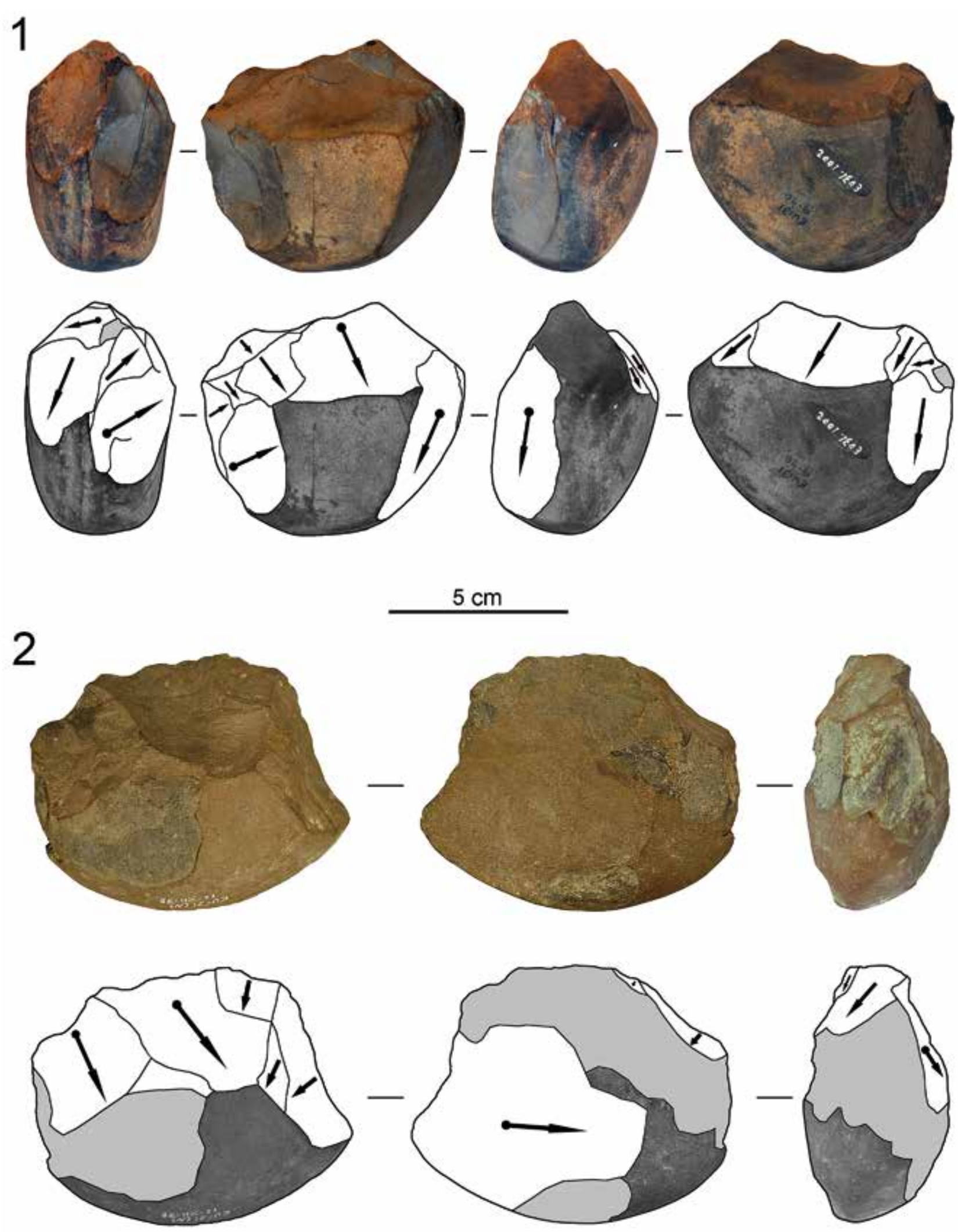

Fig.8. Artefactos sobre canto. 1) Canto tallado bifacial (raedera denticulada). 2) Canto tallado bidireccional (raedera latero-transversal). Los negativos resaltados en gris son consecuencia de alteraciones recientes / Knapped pebbles. 1) Bifacial pebble (denticulate side scraper). 2) Bidirectional knapped pebble (lateral-transversal side scraper). The grey area in the drawing correspond with actual alteration. 

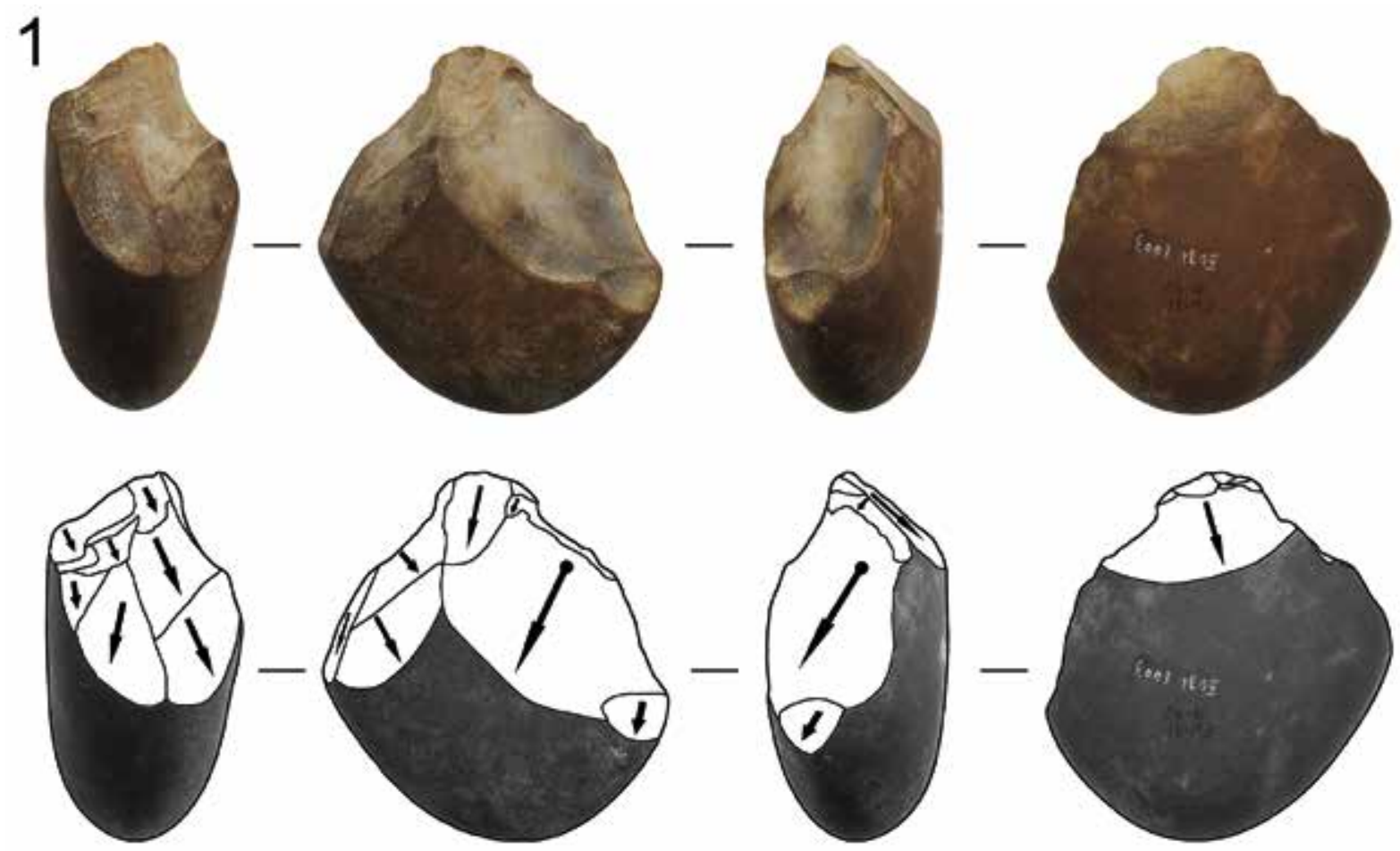

$5 \mathrm{~cm}$

2
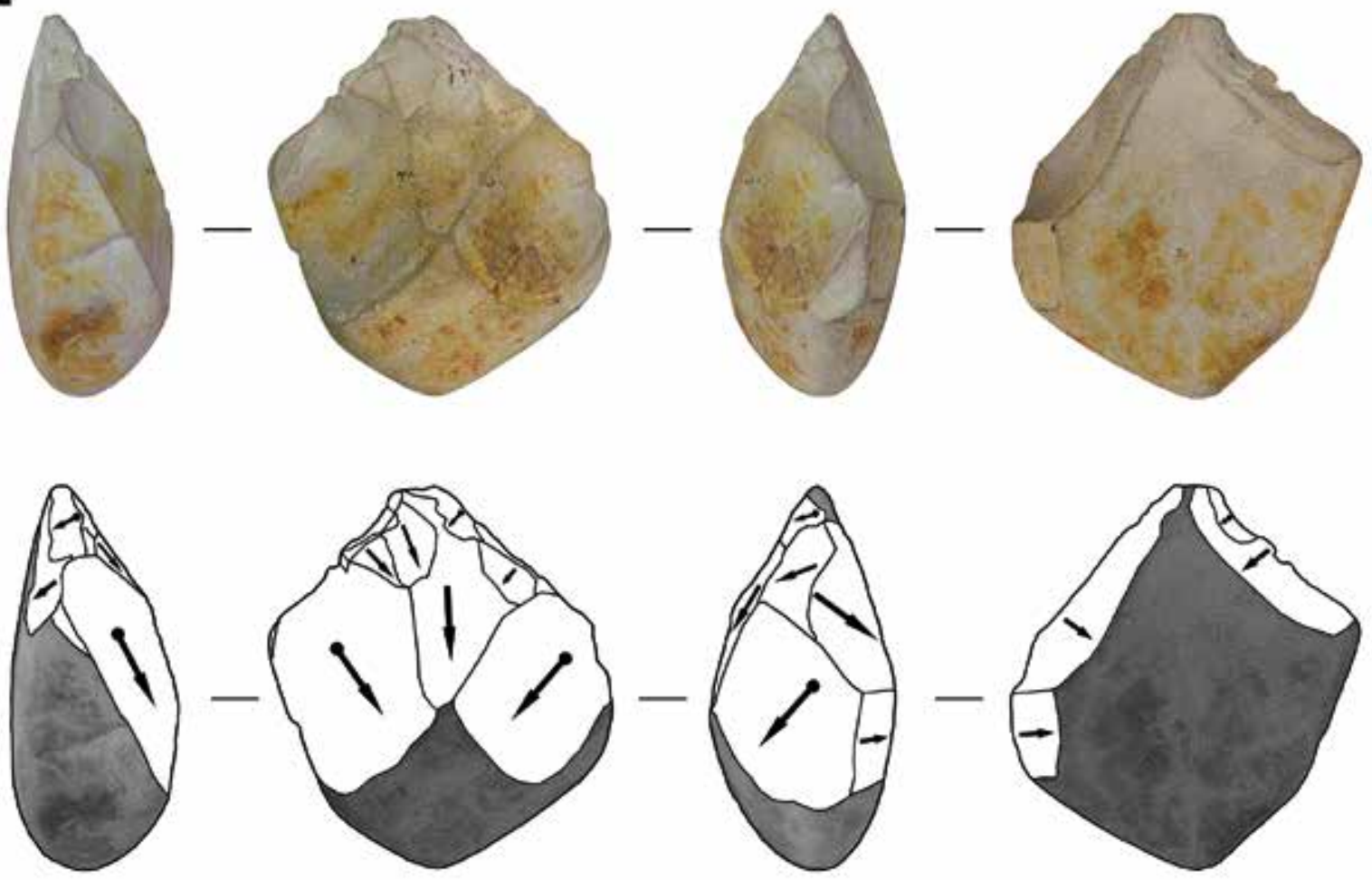

Fig.9. Artefactos sobre canto de talla bidireccional. 1) Raedera denticulada. 2) Punta simple / Bidirectional knapped pebbles. 1) Denticulate side scraper. 2) Simple point. 


\subsubsection{Artefactos sobre Productos Brutos de Talla}

Hendedores: Se han estudiado un total de tres. Uno está fabricado sobre lasca y los otros dos sobre lascas laminares. Dos de ellos se configuraron mediante retoques Simple, Plano o Buril, sobreimpuestos, compuestos o alternos. El tercero, sobre gran lasca laminar, el golpe que conforma el filo no podemos definirlo como retoque propiamente dicho sino que es fruto de una extracción previa a la extracción de la lasca laminar. Se podría asociar al tipo 1 de la clasificación de Tixier (1956) (Fig.6.2.).
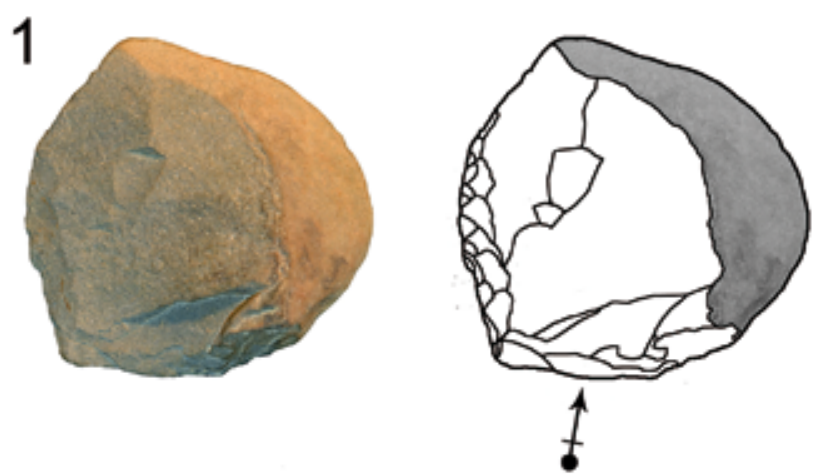

$5 \mathrm{~cm}$

4
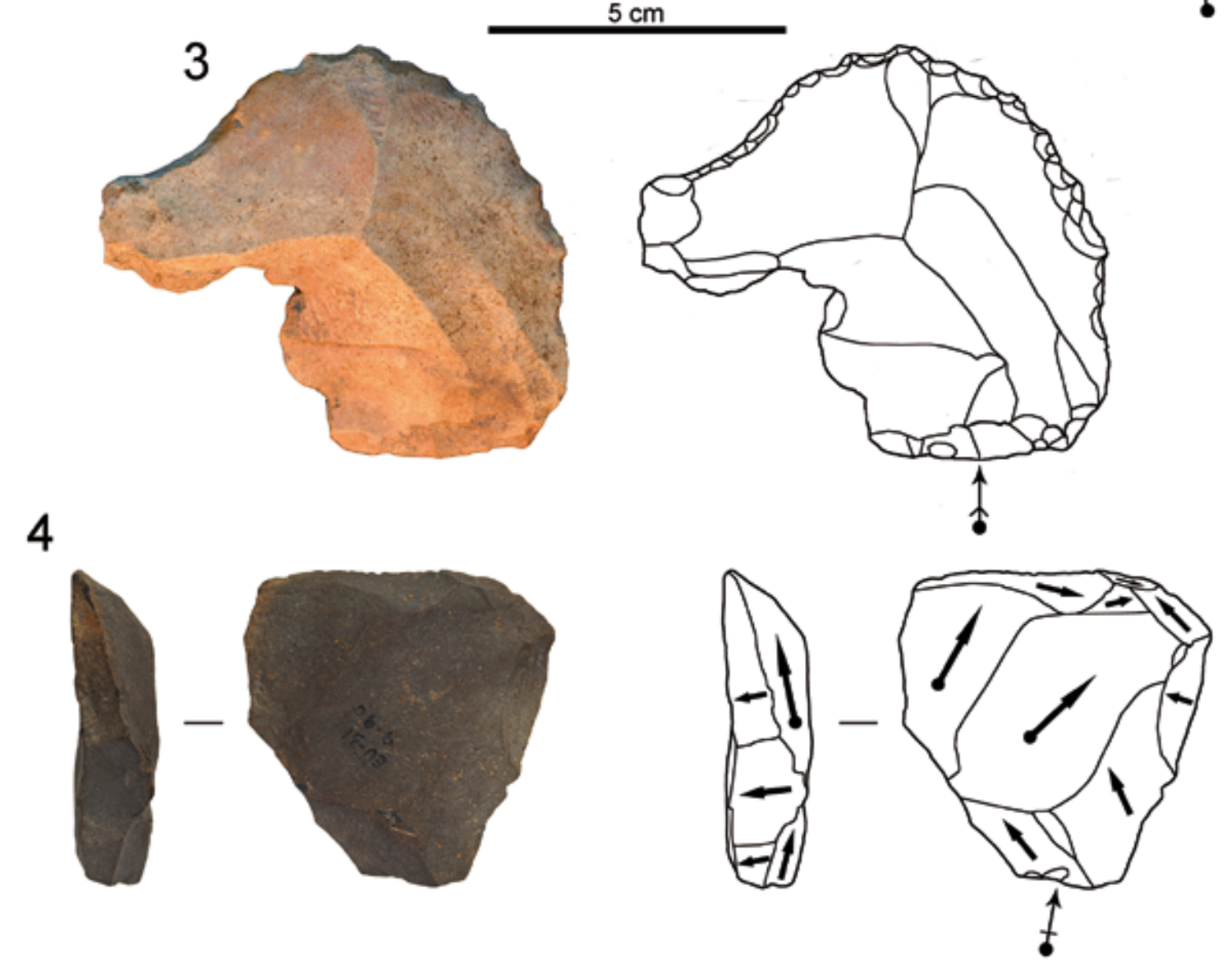

Raederas: Se recuperaron tres individuos de los que dos se identificas con raederas laterales (R1) y, la tercera, con una raedera latero-transversal (R3) (Fig.10.1).

Las raederas laterales (R1) están, configuradas a partir de retoque Simple profundo, localizado en el lateral izquierdo y, la otra, sobre lasca con retoques Simples, marginales en el lateral izquierdo.

La raedera latero-transversales (R3), por su parte, conforma un artefacto compuesto con una espina (D2) obtenido mediante retoque Simple y profundo. La espina se desarrolla en el lateral izquierdo.

Fig.10. Útiles retocados sobre Productos Bruto de Talla y Producto Bruto de Talla sin retocar. 1) Raedera unilateral. 2) Espina. 3) Raspador denticulado. 4) Lasca / Retouched blank and non-retouched blank. 1) Unifacial side scraper. 2) Spine. 3) Scraper. 4) Flake. 
Puntas: De este grupo se recuperó una punta simple (P1) fabricada sobre producto alargado y presenta retoques Simples, profundos, opuestos y convergentes.

Denticulados: Dentro de este grupo tipológico se han clasificado y estudiado ocho artefactos. De ellos, dos se identifican con espinas (D2) (Fig.10.2), cinco con raederas denticuladas (D3) y uno con un raspador denticulado (D5).

Espinas (D2) se han contabilizado tres, una compuesta con una raedera latero-transversal (R3), descrita anteriormente, y dos conforman artefactos en sí mismos. En un caso está realizada sobre lasca-laminar $y$, en el otro, en una lasca. Los retoques que las configuran son Simples, muy profundos y directos, para la lasca-laminar, e inversos para la lasca.

Raederas denticuladas (D3) son cinco elaboradas sobre lasca, en todos los casos están ejecutadas mediante retoque Simple, marginal, en un caso, y, en el resto, profundo o muy profundo.

Raspador denticulado (D5) se ha estudiado solo un ejemplar realizado sobre lasca. El artefacto se localiza en el extremo distal del soporte y muestra composición con un retoque Simple denticulado (Fig.10.3).

Écaillé: De este grupo tipológico solamente se ha estudiado un ejemplar perteneciente el tipo primero de raedera écaillé (E1). Se manufacturó sobre una lasca y obtenida mediante retoque profundo, bifacial opuesto o inverso.

\subsection{Estructura Tecnológica}

\subsubsection{Artefactos tallados/retocado}

Los 32 objetos que configuran el grupo de las evidencias talladas y/o retocadas, se dividen a su vez, con relación al tipo de soporte, en 16 realizados sobre canto y otros 16 sobre productos de lascado.

\subsubsection{Artefactos tallados sobre canto}

Respecto al morfo-tema que configuran estas piezas, se han identificado cinco grupos tipológicos: hendedor, raederas, raspadores, puntas y denticulados. Junto a este reparto porcentual, realizamos la ordenación de los diferentes componentes atendiendo a las frecuencias relativas de cada uno de ellos y su relación con la media (Tabla II). Se observa un predomino claro de las raederas y una escasa presencia del resto de grupos tipológicos que mantienen unos valores inferiores a la media (Figura 11).

Para la descripción y análisis de los artefactos efectuados sobre canto se han tomado como elementos definitorios diferentes aspectos morfo-técnicos. En primer lugar, se ha diferenciado los objetos unifaciales de los bifaciales y de los bidireccionales. (Tabla III). El carácter unifacial, a diferencia del bifacial y bidireccional, queda limitado a la elaboración de tres raederas y un raspador. El resto de morfo-temas muestras un reparto bastante equitativo entre una talla bifacial y bidireccional.

\begin{tabular}{|c|c|c|c|c|}
\hline Grupos tipológicos & $\mathrm{N}^{\circ}$ Efectivos & $\%$ & Fr. & Fr.-m. \\
\hline Hendedor & 1 & $6,25 \%$ & 0,063 & $-0,138$ \\
\hline Raedera & 8 & $50,00 \%$ & 0,500 & 0,300 \\
\hline Raspador & 2 & $12,50 \%$ & 0,125 & $-0,075$ \\
\hline Punta & 2 & $12,50 \%$ & 0,125 & $-0,075$ \\
\hline Denticulado & 3 & $18,75 \%$ & 0,188 & $-0,013$ \\
\hline Total ( $\Sigma)$ & 16 & $100,00 \%$ & 1 & \\
\hline m. & 3,2 & 1 & 0,200 & \\
\hline
\end{tabular}

Tabla 2: Distribución de los efectivos respecto a los grupos tipológicos configurados sobre cantos / Distribution of elements according to the retouched types on pebbles.

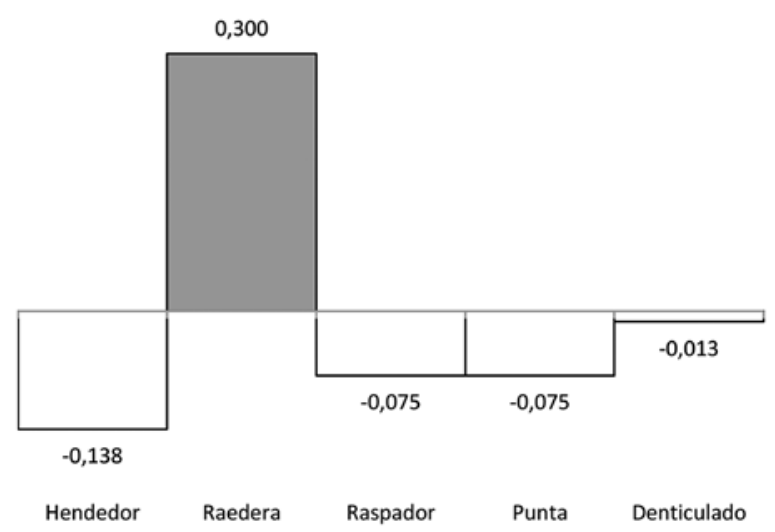

Fig.11. Representación de los grupos tipológicos configurados sobre canto a partir de las frecuencias relativas de cada categoría respecto a la media / Chart representation of each retouched types (cleaver, side scraper, scraper, point and denticulate) on pebbles based on the relative frequencies of each category in relation to the mean.

\begin{tabular}{|c|c|c|c|c|}
\hline $\begin{array}{l}\text { Grupos } \\
\text { tipológicos }\end{array}$ & Unifacial & Bifacial & Bidireccional & Total $(\Sigma)$ \\
\hline Hendedor & 0 & 1 & 0 & 1 \\
\hline Raedera & 3 & 2 & 3 & 8 \\
\hline Raspador & 1 & 0 & 1 & 2 \\
\hline Punta & 0 & 1 & 1 & 2 \\
\hline Denticulado & 0 & 2 & 1 & 3 \\
\hline Total $(\Sigma)$ & 4 & 6 & 6 & 16 \\
\hline$\%$ & $25,00 \%$ & $37,50 \%$ & $37,50 \%$ & $100,00 \%$ \\
\hline
\end{tabular}

Tabla 3: Reparto de los cantos tallados, unifaciales, bifaciales y bidireccionales / Distribution of retouched pebbles according to the unifacial, bifacial and bidirectional exploitation.

Otro aspecto técnico derivado de la realización de una talla unifacial, bifacial o bidireccional es la delineación de la arista. Se han contemplado dos variables; rectilínea y sinuosa. La identificación de cada tipo de delineación se ha relacionado con los diferentes morfo-temas y el resultado se muestra en la tabla IV.

La delineación de la arista puede aproximarnos a entender el mecanismos de talla de los diferentes artefactos, de tal modo que la sinuosa se asocia a una talla alterna o sobreimpuesta de carácter bifacial o bilateral, en cambio la rectilínea se vincula a una talla unifacial. A su vez, los 


\begin{tabular}{|c|c|c|c|}
\hline Grupos tipológicos & Rectilíneo & Sinuosa & Total $(\Sigma)$ \\
\hline Hendedor & 1 & 0 & 1 \\
\hline Raedera & 3 & 5 & 8 \\
\hline Raspador & 1 & 1 & 2 \\
\hline Punta & 0 & 2 & 2 \\
\hline Denticulado & 0 & 3 & 3 \\
\hline Total $(\Sigma)$ & 5 & 11 & 16 \\
\hline$\%$ & $31,25 \%$ & $68,75 \%$ & $100,00 \%$ \\
\hline
\end{tabular}

Tabla 4: Variación de la delineación de la arista de los cantos tallados / Variation on edge delineation (rectilinear or sinuous edges) on retouched pebble.

diferentes morfo-temas se asocian a uno u otro tipo de talla. Las puntas y los denticulados a una talla alterna o sobreimpuesta, dando como resultado aristas sinuosas. En cambio, el raspador y las raederas se asocia tanto a una talla unifacial como bifacial, dando como resultado aristas rectilíneas o sinosas dependiendo de la dinámica de golpearlo durante su talla. El hendedor, por su parte, muestra una talla bifacial en los laterales aunque la arista que define el morfo-tema es rectilínea y transversal.

\subsubsection{2. Útiles sobre Productos Brutos de Talla}

En total se han identificado 16 piezas. Además, se ha realizado también la ordenación interna de los diferentes artefactos con relación a la media (Tabla V). Se observa un claro predominio de los denticulados. El resto de morfo-temas muestran valores inferiores a la media salvo el grupo de los hendedores (Figura 12).

\begin{tabular}{|c|c|c|c|c|}
\hline Grupos tipológicos & $\mathrm{N}^{\circ}$ Efectivos & $\%$ & Fr. & Fr.-m. \\
\hline Hendedor & 3 & $18,75 \%$ & 0,188 & 0,045 \\
\hline Raedera & 2 & $12,50 \%$ & 0,125 & $-0,018$ \\
\hline Punta & 1 & $6,25 \%$ & 0,063 & $-0,080$ \\
\hline Denticulado & 8 & $50,00 \%$ & 0,500 & 0,357 \\
\hline Ecaillé & 1 & $6,25 \%$ & 0,063 & $-0,080$ \\
\hline Compuestos & 1 & $6,25 \%$ & 0,063 & $-0,080$ \\
\hline Total $(\Sigma)$ & 16 & $100,00 \%$ & 1 & \\
\hline m. & 2,286 & & 0,143 & \\
\hline
\end{tabular}

Tabla 5: Reparto de los efectivos con relación a los morfo-temas configurados sobre Productos Brutos de Talla. / Distribution of elements according to the retouched types on blanks.

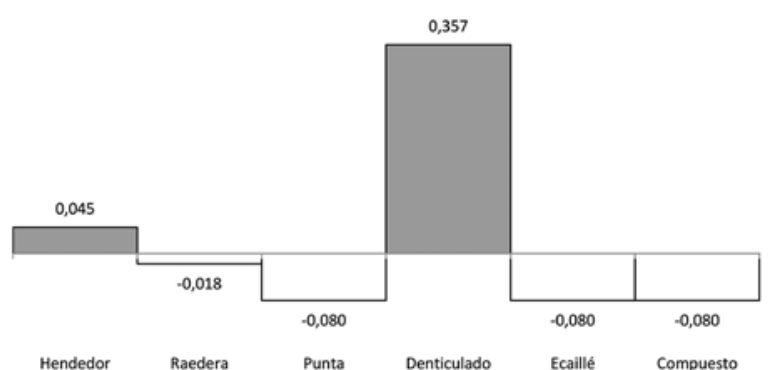

Fig.12. Ordenación interna de los grupos tipológicos configurados sobre Productos Brutos de Talla con relación a la media / Chart representation of the internal organization of the retouched types (cleaver, side scraper, scraper, point and denticulate) on blanks based on the relative frequencies of each category in relation to the mean.
El soporte preferencial es de tipo lasca frente a la escasa presencia de productos alargados como láminas y lascas laminares (Tabla VI). A su vez, para profundizar en las características técnicas de dichos soportes se ha analizado la orientación de los negativos que presentan en sus caras dorsales, de tal forma que se han identificado aquellos que presentan una, dos o múltiples orientaciones, más un grupo que no presentan negativos puesto que su cara dorsal es cortical (Tabla VII).

\begin{tabular}{|c|c|c|c|c|}
\hline $\begin{array}{l}\text { Grupos } \\
\text { tipológicos }\end{array}$ & Lasca & Lámina & Lasca Laminar & Total $(\Sigma)$ \\
\hline Hendedor & 1 & 0 & 2 & 3 \\
\hline Raedera & 2 & 0 & 0 & 2 \\
\hline Punta & 0 & 1 & 0 & 1 \\
\hline Denticulado & 7 & 0 & 1 & 8 \\
\hline Ecaillé & 1 & 0 & 0 & 1 \\
\hline Compuestos & 1 & 0 & 0 & 1 \\
\hline Total $(\Sigma)$ & 12 & 1 & 3 & 16 \\
\hline$\%$ & $75,00 \%$ & $6,25 \%$ & $18,75 \%$ & $100,00 \%$ \\
\hline
\end{tabular}

Tabla 6: Reparto de los efectivos con relación a los morfo-temas y al soporte / Distribution of retouched blanks according to the blank types.

\begin{tabular}{|c|c|c|c|c|c|}
\hline Soportes & $\begin{array}{c}\text { Sin } \\
\text { Orient. }\end{array}$ & $\begin{array}{c}1 \\
\text { Orient. }\end{array}$ & $\stackrel{2}{2}$ Orient. & Múltiples & $\begin{array}{c}\text { TOTAL } \\
(\Sigma)\end{array}$ \\
\hline Lasca & 4 & 5 & 1 & 2 & 12 \\
\hline Lasca laminar & 0 & 1 & 1 & 1 & 3 \\
\hline Lámina & 0 & 1 & 0 & 0 & 1 \\
\hline Total $(\Sigma)$ & 4 & 7 & 2 & 3 & 16 \\
\hline$\%$ & $25,00 \%$ & $43,75 \%$ & $12,50 \%$ & $18,75 \%$ & $100,00 \%$ \\
\hline
\end{tabular}

Tabla 7: Reparto de los soporte con relación a las orientaciones de los negativos de las caras dorsales / Distribution of blanks types according to the orientation of negative scars on dorsal surface.

En los productos de una orientación, se ha identificado el tipo de dirección que mantienen los negativos. Encontramos direcciones directas e inversas; la suma de estas dos direcciones, más aquellas realizadas desde la izquierda o desde la derecha (Tabla VIII). Como resultado obtenemos una diversidad heterogénea en la que no predomina un tipo sobre otro.

Por último hemos analizado los talones. Se han distinguido cuatro tipos, cortical, liso, diedro y facetado, que se han relacionado con los distintos soportes controlados (Tabla IX). Aunque contamos con un número reducido de efectivos, podemos apreciar una presencia mayoritaria de los talones lisos en todas las formas, seguido de los corticales, circunscrito a las lascas, y la baja presencia de facetados junto a diedros.

\subsubsection{Productos Brutos de Talla}

Dentro de este grupo solo se han identificado 13 individuos. Este hecho hace que tengamos que reagrupar los 32 grupos propuesto por Bagolini a tres formas generales; lasca, lámina y lasca laminar. A nivel cuan- 


\begin{tabular}{|c|c|c|c|c|c|c|}
\hline 1 Orientación & Directas & Indirectas & Directas-Indirectas & Dextras & Senestras & 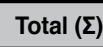 \\
\hline Lasca & 2 & 1 & 0 & 1 & 1 & 5 \\
\hline Lasca-laminar & 0 & 0 & 1 & 0 & 0 & 1 \\
\hline Lámina & 1 & 0 & 0 & 0 & 0 & 1 \\
\hline Total $(\Sigma)$ & 3 & 1 & 1 & 1 & 1 & 7 \\
\hline$\%$ & $42,86 \%$ & $14,29 \%$ & $14,29 \%$ & $14,29 \%$ & $14,29 \%$ & $100,00 \%$ \\
\hline
\end{tabular}

Tabla 8: Reparto de los soporte con relación a las direcciones de los negativos de las caras dorsales adscritas a los productos con una orientación / Distribution of blanks types according to the direction of negative scars on dorsal surface on blanks with one orientation.

\begin{tabular}{|c|c|c|c|c|c|}
\hline Tipos detalón & Cortical & Liso & Diedro & Facetado & 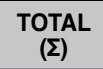 \\
\hline Lasca & 4 & 6 & 2 & 0 & 12 \\
\hline Lasca laminar & 0 & 2 & 0 & 1 & 3 \\
\hline Lámina & 0 & 1 & 0 & 0 & 1 \\
\hline Total $(\Sigma)$ & 4 & 9 & 2 & 1 & 16 \\
\hline$\%$ & $25,00 \%$ & $56,25 \%$ & $12,50 \%$ & $6,25 \%$ & $100,00 \%$ \\
\hline
\end{tabular}

Tabla 9: Reparto de los soporte con relación a los tipos de talón / Distribution of blanks according to the type of striking platform.

titativo se observa un predomino de las lascas frente a formatos alargados (Tabla X). En consecuencia a esta primera aproximación morfo-métrica, se aprecia una sobrerrepresentación de las lascas respecto al resto de formas (Figura 13).

Esta distribución es similar a la observada en el análisis de los soportes de los productos retocados sobre Productos Brutos de Talla, los cuales se caracterizan por una morfología mayoritaria de tipo lasca frente a productos alargados (Fig.10.4).

\begin{tabular}{|c|c|c|c|c|}
\hline Clases & $\mathrm{N}^{\circ}$ Efectivos & $\%$ & Fr. & Fr.-m. \\
\hline Lasca (+Frag.) & 11 & $84,62 \%$ & 0,846 & 0,513 \\
\hline Lasca-laminar & 1 & $7,69 \%$ & 0,077 & $-0,256$ \\
\hline Lámina & 1 & $7,69 \%$ & 0,077 & $-0,256$ \\
\hline Total $(\Sigma)$ & 13 & $100,00 \%$ & 1 & \\
\hline m. & 4,333 & & 0,333 & \\
\hline
\end{tabular}

Tabla 10: Reparto de los Productos Brutos de Talla con relación a la forma Distribution of elements according to the type of blank.

0,513

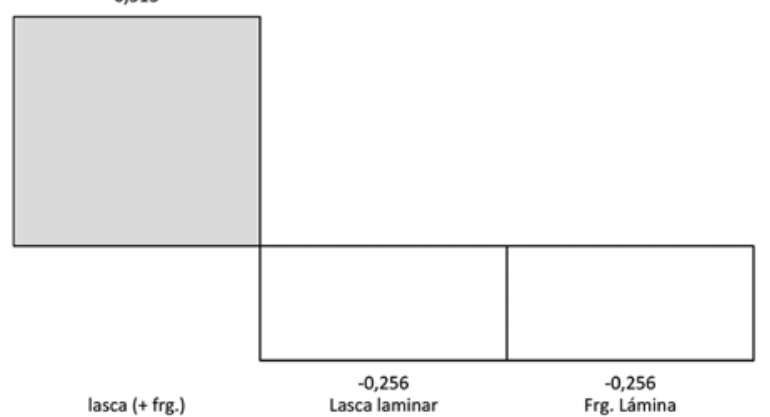

Fig.13. Ordenación interna de los grupos de productos brutos de talla con relación a la media / Chart representation of each blank by metrical characterization (flake, blading-flake or blade) based on the relative frequencies of each category in relation to the mean.
Así pues, para comprobar si existe un nexo técnico entre los productos retocados y los Productos Brutos de Talla, se han relacionado el número de orientaciones que mantienen los negativos de las caras dorsales de los soportes retocados con los que no lo tienen (Tabla $X I$ ). El reparto cuantitativo entre ambas categorías demuestra unas similitudes técnicas, a excepción de los elementos que no presentan orientaciones en su cara dorsal Este hecho puede que se deba a un problema de conservación o visibilidad, puesto que los Productos Brutos de Talla que carecen de negativos en su cara dorsal se hayan podido equiparar con elementos naturales en los procesos de recogida del material lítico.

\begin{tabular}{|l|c|c|c|c|c|}
\hline Categorías & $\begin{array}{c}\text { Sin } \\
\text { Orient. }\end{array}$ & $\begin{array}{c}\mathbf{1} \\
\text { Orient. }\end{array}$ & $\begin{array}{c}\mathbf{2} \\
\text { Orient. }\end{array}$ & Múltiples & $\begin{array}{c}\text { TOTAL } \\
(\Sigma)\end{array}$ \\
\hline PBT & 1 & 6 & 3 & 3 & 13 \\
\hline $\begin{array}{l}\text { Tallado/ } \\
\text { Retocado }\end{array}$ & 4 & 7 & 2 & 3 & 16 \\
\hline Total $(\boldsymbol{\Sigma})$ & 5 & 13 & 5 & 6 & 29 \\
\hline$\%$ & $17,24 \%$ & $44,83 \%$ & $17,24 \%$ & $20,69 \%$ & $100,00 \%$ \\
\hline
\end{tabular}

Tabla 11: Comparación de las orientaciones de los negativos de los Productos Brutos de Talla y los soportes. / Distribution of the main analysis categories with the orientation of negative scars on dorsal surface.

La ordenación interna nos demuestra una concordancia entre los soportes retocados y los Productos Brutos de Talla (Figura 14), manteniendo unos caracteres morfo-técnicos equivalentes salvo en los productos corticales, los cuales mantienen una visibilidad mayor entre los artefactos retocados (Tabla XII).

Por último, comparamos los diferentes tipos de taIones entre los Productos Brutos de Talla y los soportes (Tabla XIII). Se observa un predominio de los talones lisos tanto en los soportes como en los Productos Brutos de TaIla, la única diferencia se encuentra en los talones diedros y facetados. El primero es más notable en los soportes y el segundo en los Productos Brutos de Talla. Además los talones corticales se vinculan a los productos retocados, hecho que viene a verificar un posible sesgo en el registro.

\subsubsection{Núcleos}

Son un total de 25 objetos que se han dividido en discoides bifaciales y unifaciales, levallois, polarizados y polidireccionales (Tabla XIV). Observamos un claro predominio de los núcleos que muestran una reducción 


\begin{tabular}{|l|c|c|c|c|c|c|c|}
\hline & & Sin Orient. & 1 orient. & 2 Orient. & Múltiples & Total ( $\Sigma)$ & m. \\
\hline PBT & N. & 1 & 6 & 3 & 3 & 13 & 3,250 \\
\hline & Fr. & 0,077 & 0,462 & 0,231 & 0,231 & 1 & 0,250 \\
\hline & Fr.m. & $-0,173$ & 0,212 & $-0,019$ & $-0,019$ & - & - \\
\hline Retoque & N. & 4 & 7 & 2 & 3 & 316 & 4 \\
\hline & Fr. & 0,251 & 0,438 & 0,125 & 0,188 & 1 & 0,250 \\
\hline & Fr.m. & 0,001 & 0,188 & $-0,125$ & $-0,063$ & - & - \\
\hline $\begin{array}{l}\text { PBT + } \\
\text { Retoque }\end{array}$ & N. & 5 & 13 & 5 & 6 & 29 & 7,25 \\
\hline & Fr. & 0,172 & 0,448 & 0,172 & 0,207 & 1 & 0,250 \\
\hline & Fr.m. & $-0,078$ & 0,198 & $-0,078$ & $-0,043$ & - & - \\
\hline
\end{tabular}

Tabla 12: Distribución las diferentes orientaciones de los negativos de las caras dorsales de los Productos Brutos de Talla, soportes retocados y la suma de ambos con relación a la media / Distribution of the main analysis categories and the orientation of negative scars on dorsal surface based on the relative frequencies.

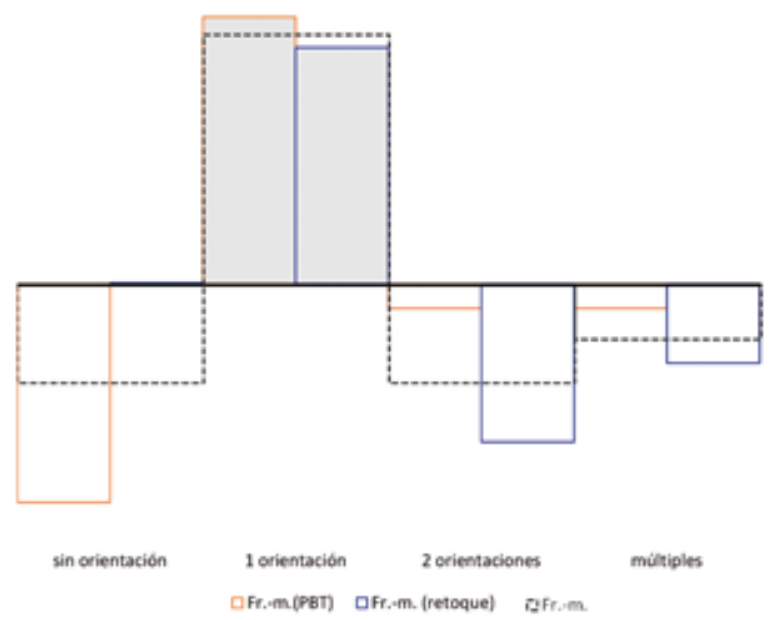

Fig.14. Ordenación interna de los grupos de productos brutos de talla con relación a la media / Chart representation of different orientation of negative scars on dorsal surface (without position, 1, 2, or 3 or more orientation) based on the relative frequencies of each category in relation to the mean Red colour represent non-retouched blanks and blue colour retouched blanks. Discontinuous black line represent the mean of each different position negative scars on dorsal surface

\begin{tabular}{|c|c|c|c|c|c|c|c|}
\hline & & Cortical & Liso & Diedro & Facetado & Aplastado & 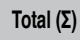 \\
\hline \multirow[t]{3}{*}{ PBT } & $\begin{array}{c}\text { Lasca } \\
\text { (+ frag) }\end{array}$ & 1 & 6 & 0 & 3 & 1 & 11 \\
\hline & $\begin{array}{l}\text { Lasca- } \\
\text { laminar }\end{array}$ & 0 & 1 & 0 & 0 & 0 & 1 \\
\hline & $\begin{array}{l}\text { Láminas } \\
\text { (+frag) }\end{array}$ & 0 & 0 & 0 & 1 & 0 & 1 \\
\hline \multirow[t]{5}{*}{ Retoque } & Lasca & 4 & 6 & 2 & 0 & 0 & 12 \\
\hline & $\begin{array}{l}\text { Lasca- } \\
\text { laminar }\end{array}$ & 0 & 2 & 0 & 1 & 0 & 3 \\
\hline & Lámina & 0 & 1 & 0 & 0 & 0 & 1 \\
\hline & 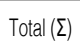 & 5 & 16 & 2 & 5 & 1 & 29 \\
\hline & $\%$ & $17,24 \%$ & $55,17 \%$ & $6,90 \%$ & $17,24 \%$ & $3,45 \%$ & $100,00 \%$ \\
\hline
\end{tabular}

Tabla 13: Comparación de los talones de los Productos Brutos de Talla y los soportes / Comparación de los talones de los Productos Brutos de Talla y los soportes. centrípeta de tipo discoide unifacial (Figura 15).La mayoría de los núcleos se inscriben dentro del grupo de los discoides, unifaciales (Fig.16) más que bifaciales (Fig.17). Frente a este grupo mayoritario se han identificado dos levallois (Fig.18), tres polarizados y uno polidireccional. En la organización interna de los diferentes tipos de núcleo se indica, además, la diferenciación de aquellos que presentan una reducción centrípeta o no.

\begin{tabular}{|c|c|c|c|c|}
\hline Categorías & $\mathrm{N}^{\circ}$ Efectivos & $\%$ & Fr. & Fr.-m. \\
\hline Discoide Unifacial & 15 & $60 \%$ & 0,600 & 0,400 \\
\hline Discoide Bifacial & 4 & $16 \%$ & 0,160 & $-0,040$ \\
\hline Levallois & 2 & $8 \%$ & 0,080 & $-0,120$ \\
\hline Polarizado & 3 & $12 \%$ & 0,120 & $-0,080$ \\
\hline Polidireccional & 1 & $4 \%$ & 0,040 & $-0,160$ \\
\hline Total $(\Sigma)$ & 25 & $100,00 \%$ & 1 & - \\
\hline $\mathrm{m}$. & 5 & - & 0,200 & - \\
\hline
\end{tabular}

Tabla 14: Comparación de los talones de los Productos Brutos de Talla y los soportes / Distribution of elements according to core types.

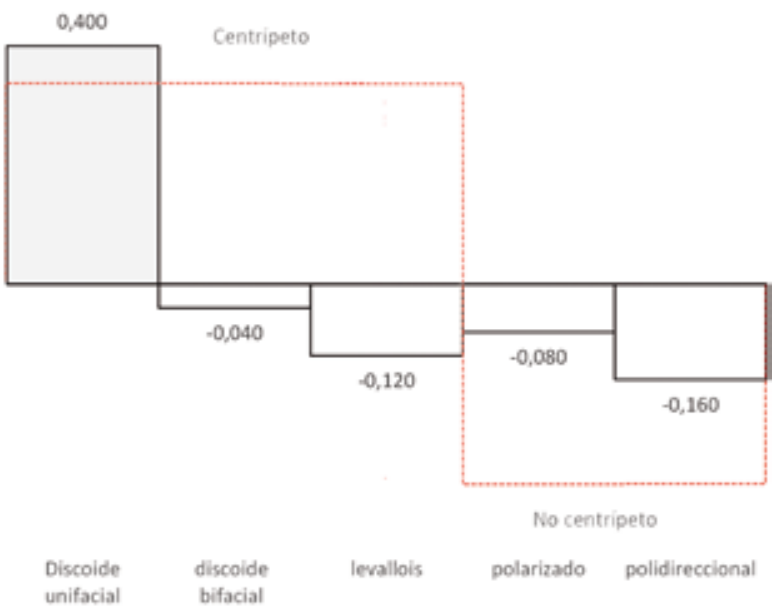

Fig.15. Tipos de núcleos y su ordenación interna conforme a la media / Chart representation of types of cores (Unifacial centripetal core, bifacial centripetal core, levallois core, polarised core, and multidirectional core) based on the relative frequencies of each category in relation to the mean. Discontinuous red line represent general categories of centripetal or non-centripetal cores.

\subsection{Estructura Tipométrica}

Para finalizar realizamos una comparativa métrica entre los núcleos, Productos Brutos de Talla, cantos tallados y artefactos retocados. Para ello se han modelizado las tres categorías tomando como referencia las longitudes máximas y representadas en una campana de Gauss (Fig. 19).

Se puede apreciar que tanto los núcleos como los cantos tallados se comportan de una manera más homogénea respecto a su distribución, encontrando la diferencia en el tamaño medio. Los cantos tienen una media de 9,2 cm, mientras que la de los núcleos es menor $(7,7 \mathrm{~cm})$. 

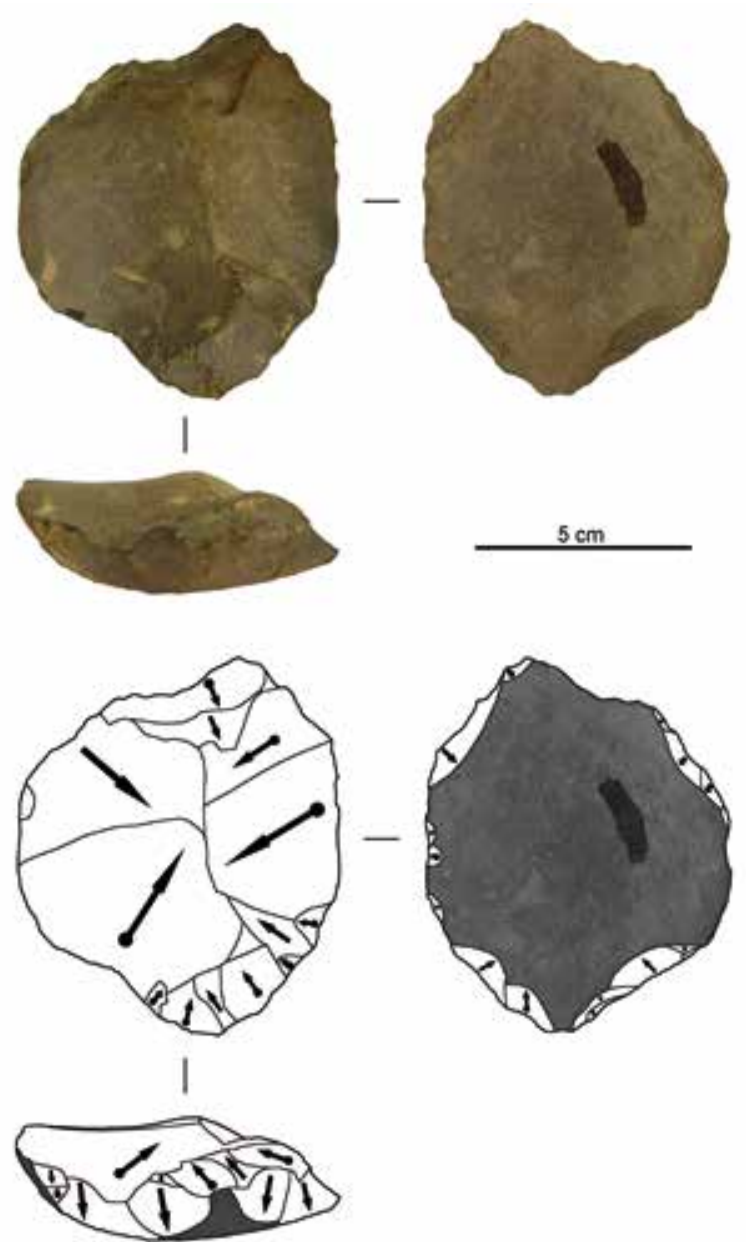

Fig.16. Núcleo centrípeto discoide unifacial / Unifacial centripetal core.
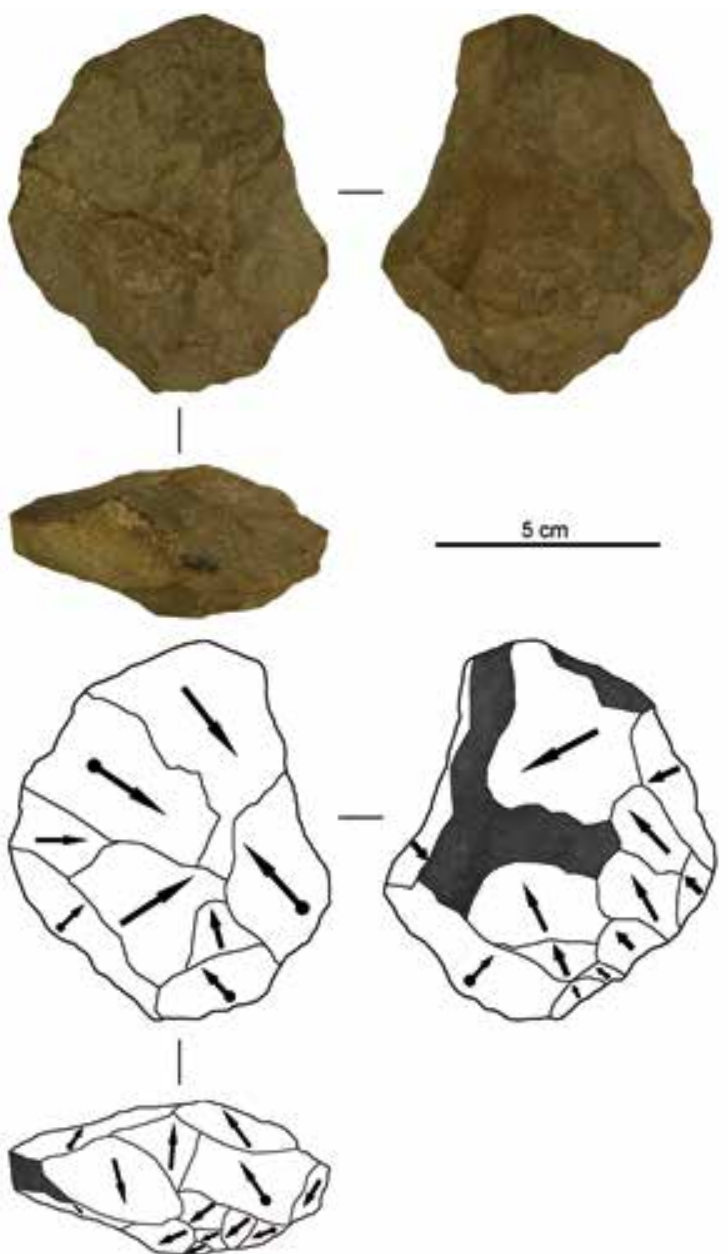

Fig.17. Núcleo centrípeto discoide bifacial / Bifacial centripetal core.

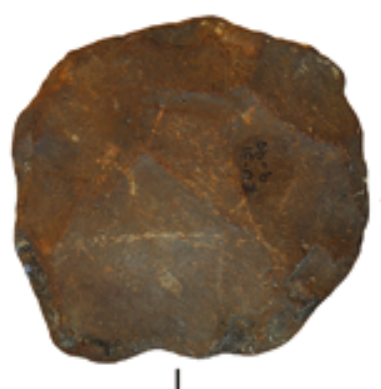

I
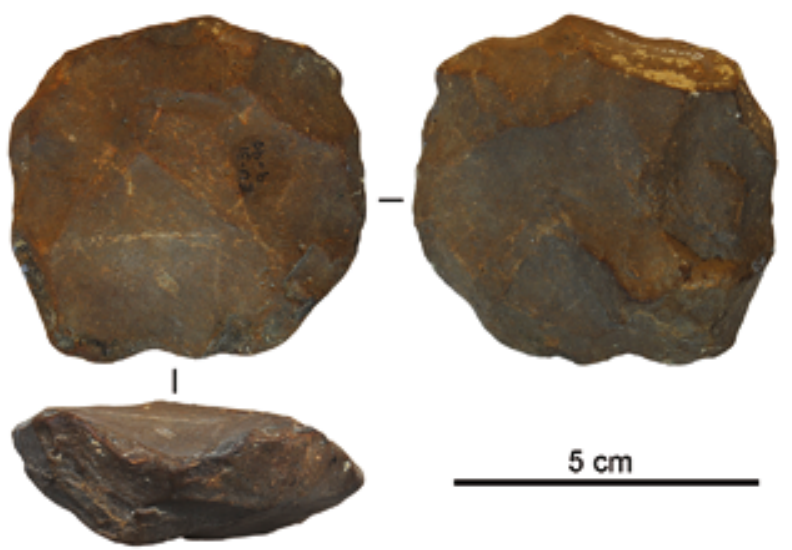

$5 \mathrm{~cm}$

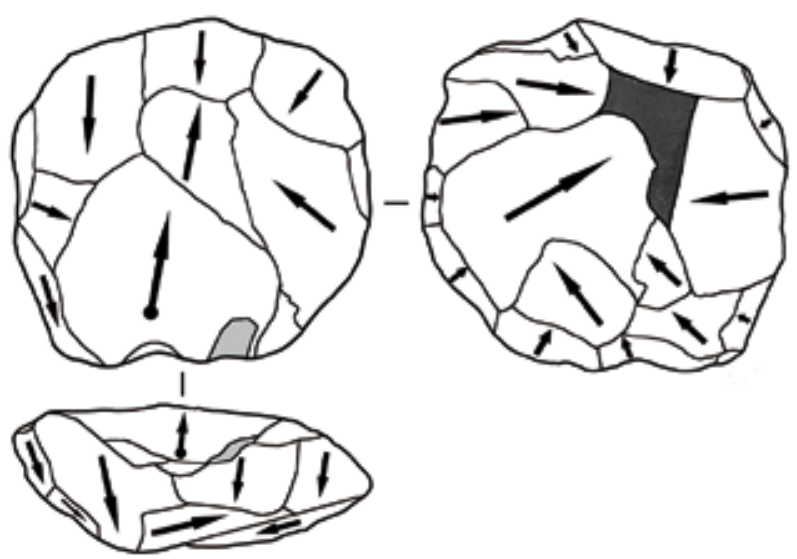

Fig.18. Núcleo Levallois. El negativo resaltado en gris se trata de una alteración reciente / Levallois core. The negative grey scar correspond with a new scar. 


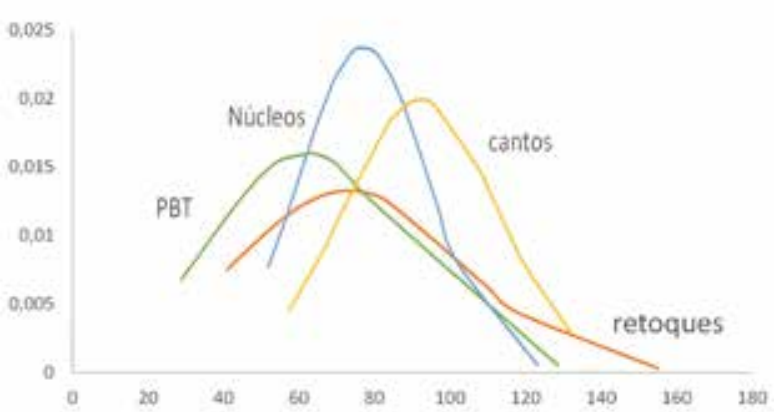

Fig.19. Curva de distribución de los productos tallados, retocados, Productos Brutos de Talla (PBT) y núcleos / Knapped pebble, cores, blank and retouched material normalized distribution.

Los Productos Brutos de Talla y los artefactos realizados sobre este tipo de soporte mantienen a su vez ciertas semejanzas. Su modelización nos indica que se organizan conforme a la media de manera similar si bien los Productos Brutos de Talla conforman una población más uniforme. Los productos retocados por su parte muestran una dispersión mayor y refleja una población más heterogénea desde un punto de vista métrico, debido posiblemente a la modificación del soporte a partir del retoque.

\section{INTERPRETACIÓN Y CONTEXTUALIZACIÓN}

Una vez realizado el análisis cuantitativo de todas las evidencias líticas, podemos destacar una serie de resultados relacionados con las materias primas empleadas y con los diversos procesos técnicos de configuración de los artefactos.

Al amparo de los datos generados en el análisis de los materiales podemos destacar una serie de evidencias morfo-técnicas que caracterizan los artefactos expuestos en este trabajo. Somos conscientes de la naturaleza particular del contexto en el que se han recuperado las diferentes evidencias líticas. Aun así fruto de la aplicación sistemática de una serie de criterios tecno-tipológicos, hemos podido establecer unos parámetros definitorios que aportan coherencia técnica a todas las evidencias y permiten entenderlas como un tecno-complejo cohesionado. Tanto desde una perspectiva tecnológica como de las diferentes materias primas empleadas.

En primer lugar, parece que existe una marcada selección de las lutitas de cemento silíceo. Esto, nos hace reflexionar sobre las posibles cualidades de mecánica de fractura que presenta este tipo de roca, la cual genera un concoide más pronunciado y unos bordes más duros que las lutitas de cemento ferruginoso o calcáreo. El aporte de materias primas es eminentemente local.

La interrelación de los diferentes caracteres morfo-técnicos contemplados en el análisis, nos indica una concordancia morfo-técnica, la cual, nos ha permitido aproximarnos a la dinámica de configuración de los ar- tefactos. Dentro de la misma entendemos dos mecanismos de producción diferenciadas, aunque comparten ciertos gestos técnicos. Por un lado la talla de elementos masivos sobre canto y por otro, la manufactura de lascas y piezas sobre estos soportes.

Con relación a los artefactos constituidos sobre canto apreciamos una escasa diversidad de morfo-temas, reducida a raederas, puntas y denticulados. Respecto a los mecanismos de elaboración podemos relacionar los diferentes caracteres técnicos con distintas dinámicas de talla. La primera de ellas, consiste en la configuración de morfo-temas a partir del trabajo de una de sus caras. Esta, de carácter unifacial, se encuentra limitada a tres raederas y un raspador y se caracterizan por dibujar una arista rectilínea. La segunda, se identifica con una talla bifacial mediante una percusión alterna en la que se trabaja de manera simultánea ambas caras del canto (Fig.7 y 19.B1). Como resultado se obtienen artefactos que presentan aristas sinuosas y los negativos de las extracciones tienen la misma amplitud en ambas caras. Por último, hemos observado ciertos artefactos que han sido configurados de forma bidireccional (Fig.8 y 20.C). Este proceso se diferencia del anterior en el mecanismo de golpeo. En este sentido, la talla bidireccional se asocia a la sobreimposición de una secuencia de golpes en una cara sobre otra trabaja previamente. Como resultado, la amplitud de los negativos de ambas caras presentan cierta asimetría y, en la mayoría de los casos, una cara conserva negativos más profundos que la otra.

El hendedor manufacturado sobre canto refleja una dinámica propia para su configuración. En este sentido, la talla se caracteriza por ser alterna en los laterales y en el extremo transversal distal se configura, mediante un único golpe, un frente rectilíneo (Fig.6).

Los núcleos se caracterizan por una reducción centrípeta de tipo discoide y unifacial, la gestión volumétrica de estos se articula a partir de una cara preferencial en la que se efectúan extracciones perimetrales. La cara opuesta, evidencia extracciones complementarias para adecuar el plano de percusión. Esta afirmación se sustenta en la relación angular entre ambas caras y la amplitud de los propios negativos. En este sentido, la cara que se establece como plano de lascado muestra extracciones más amplias con un grado de incidencia o de golpeo oblicuo o agudo. En cambio, el plano de percusión se construye mediante extracciones poco profundas y con un grado de incidencia tendente a la perpendicularidad (Fig.14 y 20.B2).

En definitiva, existen dos técnicas diferenciadas de talla que son empleadas tanto en el trabajo de los cantos como en el de los núcleos. Una talla bidireccional, en la que se prepara un plano para el trabajo del otro, y una talla bifacial alterna en la que se explotan las dos caras del producto. Además, también existe la posibilidad de que antiguos núcleos se hayan tranformado en útiles (Fig.8 y 20.C). Esta hipótesis se asienta 
en la comparación de los caracteres técnicos de los propios núcleos que componen el conjunto analizado. De los 25 que hemos estudiado 15 se caracterizan por ser discoides unifaciales. Estos, muestran una cara preferente para extraer Productos Brutos de Talla, en la cara opuesta identificamos una serie de extracciones complementarias que servirían para adecuar el plano de percusión. La articulación de estas extracciones refleja una clara similitud a la identificada en los útiles sobre canto. La diferencia entre ambos es una serie de pequeñas extracciones circunscritas a un extremo para constituir un frente activo (Fig.20.C).

La técnica de producción de soportes y la empleada para la configuración de los útiles sobre canto comparten ciertos gestos técnicos tendentes a la reducción centrípeta. La diferencia entre unos y otros queda reducida a la relación angular entre las caras. En los núcleos, al existir una cara preferente de lascado la arista se encuentra desplazada, mientras que, para los cantos tallados, la arista se encuentra centrada respecto a ambas caras. Los productos obtenidos de los núcleos y los que proceden de la talla de los cantos no presentan divergencias técnicas, dando como resultado productos de talla con formato tipo lasca, en mayor medida, y cuyos negativos de las caras dorsales muestras una diversidad de orientaciones y direcciones a lo que se le suma, en algunos casos, la presencia de córtex (Fig. 10.4). Esta misma concepción técnica, queda enfatizada desde un punto de vista tipológico en el que los morfo-temas configurados son similares en los útiles constituidos sobre Productos Brutos de Talla y aquellos realizados sobre cantos (Fig.10 y 20.E).

Desde un punto de vista métrico cada uno de los grupos establecidos presenta unas características propias. Si bien los elementos masivos como los cantos tallados y los núcleos se presentan como una población más ajustada a una medidas homogéneas, los Productos Brutos de Talla y las piezas realizadas sobre estos soportes muestran una dispersión mayor, la cual nos refleja la no existencia de estandarización conforme al tamaño. De este modo, parece que la selección de los formatos de los elementos masivos está inmersa en mecanismos de recolección de la materia prima en la que se relacionan con dos características. La primera de ellas ligada a una preferencia de tipo petrológica y basada en el uso las lutitas silíceas -frecuentes en el área que abarca el embalse actual-, y la segunda, relacionada con los formatos y dimensiones de la roca y que parecen apropiados para la talla anteriormente expuesta.

Por el contrario, los útiles sobre lasca y los Productos Brutos de Talla, carecen de una estandarización respecto a los formatos seleccionados, articulando retoques sobre cualquier producto de talla. Esto puede demostrar la elección de una gestión volumétrica de núcleos tipo discoides y cantos tallados como la más acertada para gestionar esta materia prima, en la que se obtienen Productos Brutos de Talla de tamaños variables, pero útiles para los seres humanos.
Las evidencias líticas analizadas en este trabajo y asimilables a los Modos 1 y 2 definidos por Clark (1969), han sido reconocidas en múltiples localizaciones situadas en el territorio delimitado por los embalses de Urrúnaga, Albina y Ullibarri-Gamboa. Artefactos tallados y/o retocados manufacturados sobre canto o sobre Productos Brutos de Talla y que están realizados mayoritariamente sobre lutitas, han sido descritos en diferentes estudios individuales llevados a cabo sobre materiales recogidos en Tribitu y Tribitu I (Fernández Eraso et al., 2005; Sánchez et al., 2013), Echabarri (Fernández Eraso et al., 2012) y Zabalain (Sánchez, 2012). De la misma forma, se observan en los estudios de conjunto que abarcan los yacimientos de Belaustegi, Kargaleku Norte, Kargaleku Sur, Zabalain, Ibarra, Mugarri, Ubera, Urduleta, Antzerikueta, Echabarri, Zalzabigain, Tribitu, San Prudencio, Zaratzen y Ascarguren (Sáenz de Buruaga y Urigoitia, 1986; Sáenz de Buruaga et al., 1988/1989; Fernández Eraso, 2006). También se han documentado núcleos discoides y levallois, similares a los analizados en este trabajo, en las publicaciones de las industrias líticas de Itsetsasi (Fernández Eraso et al., 2004) y Tribitu (Fernández Eraso et al., 2005), al igual que en los sitios de Zabalain, Ibarra, Mugarri, Belaustegi, Kargaleku Norte, Kargaleku Sur, Urduleta, Antzerikueta, Echabarri, Zalzabigain, Tribitu, Joxenpozu, San Prudencio, Barrillegan y Zaratzen publicados en dos estudios de conjunto (Sáenz de Buruaga et al., 1988/1989; Fernández Eraso, 2006). Por último, los Productos Brutos de Talla realizados sobre lutita y/o con soportes levallois han sido reconocidos en los análisis individuales de los lugares de Tribitu (Fernández Eraso et al., 2005) y Echabarri (Fernández Eraso et al., 2012), del mismo modo que en los yacimientos de Zabalain, Ibarra, Mugarri, Belaustegi, Kargaleku Norte, Ziolatz, Echabarri, Zalzabigain, Tribitu y Urduleta (Sáenz de Buruaga et al., 1988/1989; Fernández Eraso, 2006).

En el Territorio Histórico de Álava se han documentado más sitios en los que han aparecido materiales de estas características. A los hallazgos en superficie ya mencionados de los bifaces de Murua (Baldeón, 1974) y Aitzabal (Barandiarán, 1953), del hendedor de Peñacerrada (Baldeón, 1978a) y de la industria lítica sobre cuarcita de Mendiguri y Ondabia (Sáenz de Buruaga et al., 1994), habría que añadir algunos de los elementos líticos recogidos en superficie en el yacimiento de Manzanos (Leciñana de la Oca) situado en las graveras del río Zadorra (Baldeón y Murga, 1989) y en las terrazas de Murba (Condado de Treviño) (Baldeón, 1974), así como en el yacimiento al aire libre de ARYA-37 (Ilarduia) en la Cuenca del Río Araia (Beorlegi, 2005).

En Vizcaya una de las mayores concentraciones de materiales se ha registrado en las Cuencas del Gobela y del Udondo, en diferentes localizaciones al aire libre como Moreaga (Sopelana), Errementariena (Barrika), Aretxabaleta (Leioa), Mendibarrena (Leioa), Ondiz, (Leioa), Kurkudi (Leioa), Zientoetxe (Getxo) y Diliz (Getxo) (Rios-Garaizar et al., 2012; Rios-Garaizar 


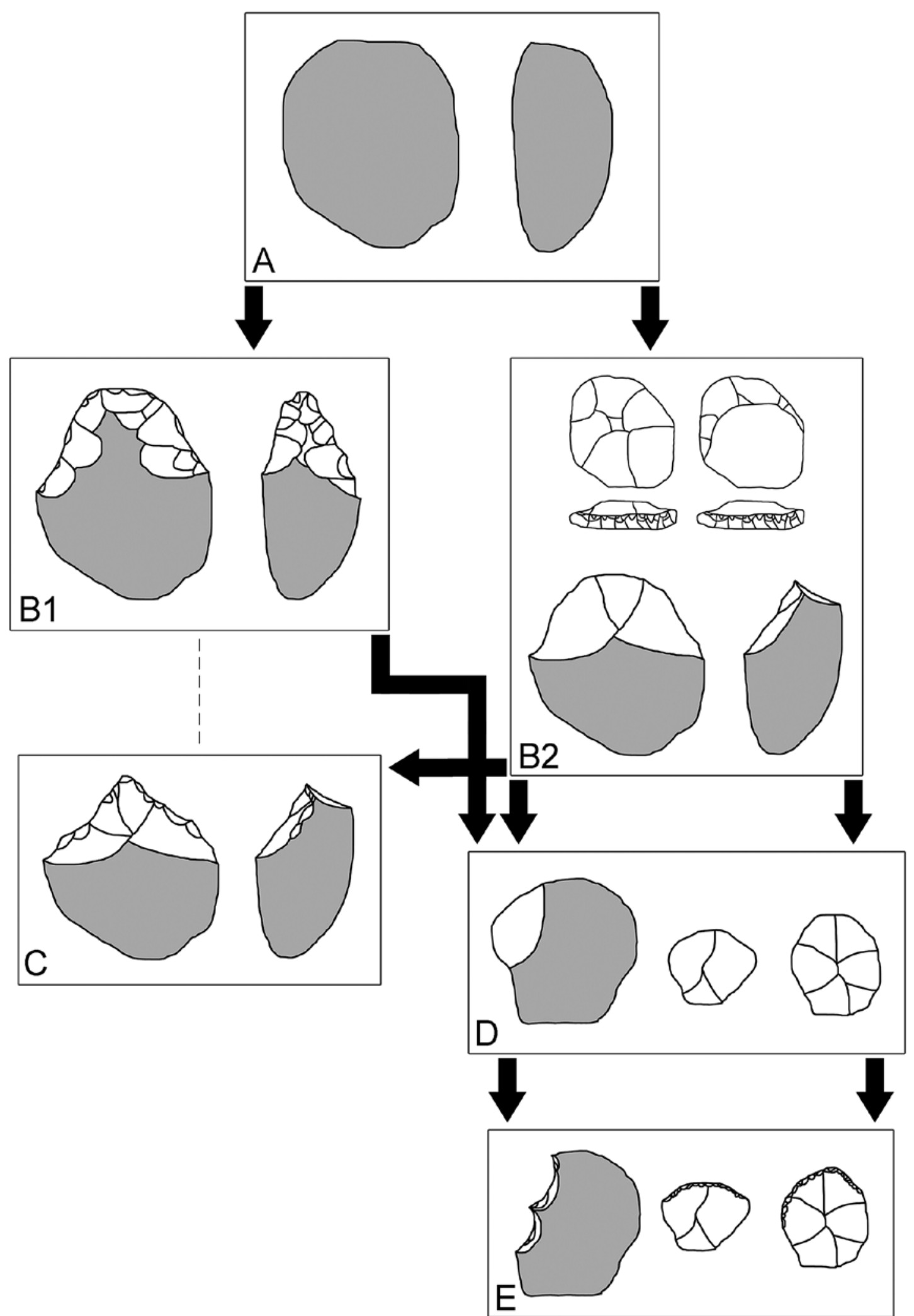

Fig.20. Esquema hipotético del proceso de explotación de los cantos presentes en el Embalse de Urrúnaga. A) Cantos en estado natural. B1) Cantos tallados unifacial o bifacialmente. B2) Núcleos sobre canto (discoides unifaciales o bifaciales y Levallois). C) Canto tallado bidireccionalmente o posible núcleo reconvertido en útil sobre canto. D) Productos Brutos de Talla. E) Utiles retocados sobre Productos Brutos de Talla / Reconstruction of knapped pebbles exploitation in Urrúnaga reservoir. A) Non-knapped pebble selected. B1) Uni- and bifacial knapped pebble. B2) Cores on pebble (discoidal, unifacial, bifacial and Levallois) C) Bidirectional knapped pebble or retouched core on pebble. D) Blanks. E) Retouched material on blanks. 
et al., 2013); y en la ocupación al aire libre de Mendieta I (Sopelana) (Rios Garaizar et al., 2010). A partir de sus características tecno-tipológicas el yacimiento de Mendieta I junto a los conjuntos de Kurkudi y Moreaga han sido adscritos a un Paleolítico inferior sin bifaces, mientras que el resto de localizaciones a un Achelense superior (Rios-Garaizar et al., 2013). Pero, sin duda, el yacimiento que cuenta con la mayor representatividad lítica es la cueva de Arlanpe (Lemoa) que contiene útiles bifaciales muy similares a los descritos en el embalse de Urrúnaga y cuyos niveles han sido adscritos al Achelense superior (Rios-Garaizar et al., 2011; Rios-Garaizar, 2013; Rios-Garaizar et al., 2015).

En Guipuzcoa existen bastantes yacimientos en los que han aparecido materiales que podrían asemejarse a los publicados en este trabajo o que, al menos, podrían pertenecer al Paleolítico inferior. Algunas menciones al respecto se han realizado de los artefactos encontrados en las cuevas de ArnaiIleta (Errezil) (Olarte, 2002; Arrizabalaga, 2005; Arrizabalaga y Rios-Garaizar, 2012), Artazu II (Arrasate) (Iriarte, 2003; Arrizabalaga, 2004), Astigarraga (Deba) (Arruabarrena et al., 2007) o Ikeitz (Zestoa) (Antxieta, 2003). Además, conocemos la existencia de un bifaz (actualmente desaparecido) recogido por Breuil en la entrada de la cueva de Aitzbitarte III (Errenteria) (Barandiarán Irizar, 1989) y la posibilidad de que algunos de los materiales de la cueva de Lezetziki (Arrasate) puedan pertenecer a un Paleolítico medio antiguo cantábrico (Baldeón, 1993; Álvarez-Alonso y Arrizabalaga, 2012). También aparecen este tipo de evidencias en yacimientos al aire libre como $\mathrm{J} 1$ e Higer en el monte Jaizkibel (Hondarribia) con mayor representación de industrias musterienses pero que una parte de ellos podrían adscribirse al Paleolítico inferior (Merino, 1986; Arrizabalaga, 1994), así como en los sectores Geltoki y Luebaki del yacimiento de Irikaitz (Zestoa) con una cronología claramente inferopaleolítica y que los estudios arqueobotánicos ubican sus ocupaciones en un momento interglaciar (Eemiense o Holsteiniense) (Arrizabalaga e Iriarte, 2002, 2004, 2008 y 2011).

En el País Vasco francés todas las evidencias de materiales similares a los estudiados en este trabajo han sido hallazgos recogidos en superficie, en muchos casos mezclados con elementos líticos de momentos más recientes. Aquellos de raigambre arcaica han sido adscritos cronoculturalmente a partir de criterios tipológicos en los diferentes periodos del Achelense, con dudas, en muchos casos, de su posible pertenencia a un Musteriense de Tradición Achelense (Arrizabalaga, 2005). Las principales zonas en las que han aparecido estas industrias son las terrazas del Adour (Passemard, 1924; Barandiarán, 1950; Thibault, 1976a, 1976b), el área de Biarritz-Anglet-Bayona, el entorno de San Juan de Luz (Laburdi) y las terrazas de la zona de Bidache/Labastide-Villefranche (Thibault, 1976a; Arambourou, 1989 y 1990; Chauchat, 1994).
Por último, en Navarra también encontramos una gran cantidad de localizaciones con materiales de estas características, si bien, en su mayor parte son artefactos recogidos en superficie. Entre ellos Coscobilo (Olazagutía) cuyos materiales fuera de contexto han sido fechados en un Musteriense de tradición Achelense debido a la presencia de bifaces en el conjunto (Beguiristain, 1974; Barandiarán y Vallespí, 1984) y el yacimientos de Matamala (Viana) en la terraza del río Ebro y que ha sido relacionados con un Achelense medio y con un Musteriense con "hendidores" (Irigaray, 1992). En Urbasa también han aparecido este tipo de industrias en los sitios de Bioiza, Pozo Laberri, Pozo Negro, Balsa de Aranzaduia y Mugarduia Norte, y que han sido adscritos de forma relativa a un periodo de transición del Achelense al Musteriense (Barandiarán y Vallespí, 1984; Barandiarán y Montes, 1991/1992). Además, se han encontrado numerosos hallazgos aislados como los bifaces de Venta de Judas (Lumbier) (Marcos Pons y Mensua, 1959; Barandiarán, 1967), de Ordoiz (Estella) (Vallespí y García Serrano, 1974), de Las Parcelas (Lezaún) (Beguiristáin, 1989) y de Cabeza Redonda (Viana) (Beguiristáin y Labeaga, 1993, Beguiristáin, 1995); así como varios bifaces más en el valle del río Ega (Armendáriz, 1997/1998), una serie de cuarcitas talladas de aspecto arcaico en Zúñiga (Obermaier, 1925) y más materiales de estas características en los alrededores de Tudela (Utrilla, 1984; Montes, 1988; Beguiristáin, 2000). Por último, debemos destacar la colección de más de 500 piezas recogidas en la Cuenca de Pamplona en los sitios de Gazólaz I y II, Ibero I-III, Paternaín I, Arazuri I, Orcoyen I y CordoviIla I-VII. Estos materiales se caracterizan, entre otras cuestiones, por no presentar elementos con soportes centrípetos y/o levallois, cuestión por la que se han fechado con reservas en un Achelense medio (García Gazólaz, 1994).

La información que presentamos constata la presencia de grupos humanos en la zona en el tránsito entre el Paleolítico inferior y medio en las estribaciones occidentales de las cadenas pirenaicas. La mayor parte de estas evidencias, carecen de información contextual y/o de otros elementos no líticos que nos permita datarlas. De este modo, el estudio de los materiales pétreos y su distribución geográfica hace que sea la única información que atestigüe un poblamiento ínfero-paleolítico en esta área. Además, la alta concentración de artefactos líticos repartidos en las orillas del embalse de Urrúnaga, muestra el uso frecuente de este lugar por parte de las comunidades paleolíticas, las cuales supieron aprovechar las características físicas del lugar y su privilegiada situación geográfica. El espacio donde hoy se emplaza el embalse supuso un lugar de abastecimiento de materias primas idóneas para manufacturar sus artefactos y una importante vía de comunicación entre la costa y la llanada alavesa mediante un corredor Norte-Sur que a su vez permite un cómodo desplazamiento hacia el Valle del Ebro y a la Meseta Castellana. 


\section{CONCLUSIONES}

La materia prima utilizada en la realización de los diferentes artefactos es, fundamentalmente, la más abundante en la zona. Así la lutita es la roca mayormente empleada y, dentro de ella, la silícea resulta claramente mayoritaria lo que denota una predilección de ésta sobre las otras.

Los artefactos estudiados en este trabajo se desarrollan, indistintamente, tanto sobre cantos como sobre Productos Brutos de Talla y produce artefactos tipológicamente muy poco variados, siendo mayoritarios los grupos de raederas y denticulados. Técnicamente, todos los elementos que componen el conjunto pueden enmarcase dentro de una misma dinámica de talla general de reducción centrípeta. Dentro de esta, existen dos técnicas diferenciadas, una de carácter bidireccional y otra bifacial, reconocidas tanto en el proceso de elaboración de los útiles sobre canto como en la reducción volumétrica de los núcleos.

De esta forma, desde un punto de vista tipológico y tecnológico el conjunto aquí analizado puede entenderse dentro de un mismo tecno-complejo que cronológicamente tampoco difiere de lo señalado para otros recuperados en el mismo vaso del embalse de Urrúnaga. En los conjuntos aquí reseñados la concurrencia de los Modos 1 y 2 se produce a finales del Paleolítico inferior y comienzos del medio. De esta manera la adscripción a un Achelense superior/final realizada en el estudio global de los primeros artefactos procedentes del embalse (Sáenz de Buruaga et al., 1988-89) parece ajustarse al nuevo conjunto aquí presentado.

Para finalizar, al amparo de los datos ofrecidos en este trabajo junto a los ya conocidos, podemos entender que el espacio donde actualmente se asienta el embalse constituyó un área de especial relevancia en las actividades económicas de captación y explotación cinegética del lugar por parte de las comunidades inferopalolíticas. A lo que hay que añadirle la importancia en cuanto al nexo de comunicación entre la zona costera inmediata con el interior peninsular y el próximo valle del Ebro. Lugar de tránsito y comunicación que ha perdurado durante todo el Paleolítico, Prehistoria reciente y hasta la actualidad.

\section{AGRADECIMIENTOS}

Este trabajo ha sido posible gracias a la financiación parcial del Grupo de Investigación en Prehistoria del Gobierno Vasco (IT622-13) y del proyecto del Ministerio Español de ciencia (HAR2014-53536-P "La ruta occidental del poblamiento de la Península Ibérica durante el Paleolítico medio y superior"). Además, A.S., A.P. y A.C están financiados por el programa Predoctoral del Departamento de Educación, Lingüística y Cultura del Gobierno Vasco (BFI-2012-205, BFI-2012121 y BFI-2011-101), M.G.R Al programa Posdoctoral del departamento de Educación, Lingüística y Cultura del Gobierno Vasco (POS-2015-1-0053) y M.B por la "Marie Curie Fellowship of the Gerda Henkel Foundation (M4HUMAN)", y el proyecto del Ministerio de las minas de Araico-Cucho (HAR2015-67429-P). Quisiéramos agradecer igualmente a Maite Iris García Collado por su ayuda en la traducción del resumen, así como a Tomás Urigoitia y Juan Antonio Madinabeitia (†) por su incansable labor de prospección llevada a cabo en el embalse de Urrúnaga.

\section{BIBLIOGRAFIA}

Álvarez-Alonso, D., Arrizabalaga, A., 2012. La secuencia estratigráfica inferior de la cueva de Lezetxiki (Arrasate, País Vasco): Una reflexión necesaria. Zephyrus 69(1), 15-39.

Antxieta, J.T., 2003. Cueva de Ikeitz. Arkeoikuska 2002, 172-175.

Arambourou, R., 1989. Préhistoire autour de Saint Jean de Luz (France). Munibe Antropologia-Arkeologia 41, 29-44.

Arambourou, R., 1990. Préhistoire en Pays Basque Nord et Sud des Landes. Munibe Antropologia-Arkeologia 42, 91-96.

Armendáriz, J., 1997-1998. Hallazgo de dos nuevos bifaces paleolíticos en el valle del río Ega. Trabajos de Arqueología Navarra 13, 349-357.

Arrizabalaga, A., 1994. Hallazgo de un bifaz y de otros restos líticos en el monte Jaizkibel (Hondarribia,Gipuzkoa). Munibe Antropologia-Arkeologia 46, 23-41.

Arrizabalaga, A., 2004. Cueva de Artazu II (Arrasate, Gipuzkoa). Arkeoikuska 2003, 371-373.

Arrizabalaga, A., 2005. Las primeras ocupaciones humanas en el Pirineo Occidental y Montes Vascos: Un estado de la cuestión en 2005. Munibe Antropologia-Arkeologia 57, 53-70. Homenaje al Prof. Jesús Altuna, Vol. I.

Arrizabalaga, A., Iriarte-Chiapusso, M.J., 2002. El yacimiento de Irikaitz (Zestoa, Gipuzkoa): Aportación al conocimiento del Paleolítico antiguo en Euskal Herria. In: XV Congreso de Estudios Vascos 1, 115-122.

Arrizabalaga, A., Iriarte-Chiapusso, M.J., 2004. El yacimiento arqueológico de Irikaitz (Zestoa, País Vasco): Descripción del depósito y caracterización industrial de su nivel IV. In: Flor, G. (Ed.), Actas de la XI Reunión Nacional del Cuaternario. Oviedo (Asturias), 205-210, Consejería de Cultura del Principado de Asturias, Concejo de Candamo.

Arrizabalaga, A., Iriarte-Chiapusso, M.J., 2008. Irikaitz (Zestoa, País Vasco). Tafonomía dun depósito pleistocénico ao aire libre. In: Méndez Quintas, E. (Ed.), Estudos sobre Paleolítico. Homenaxe a X. M, Álvarez Blázquez, 139-162, Instituto de Estudios Miñoranos, Gondomar.

Arrizabalaga, A., Iriarte-Chiapusso, M.J., 2011. Lower and Upper Palaeolithic settlements in Irikaitz (Zestoa, Basque country, Spain): Deconstruction of a Pleistocene archaeological site in the Eastern Cantabrian range. Cuaternario y Geomorfología 25, 105-119.

Arrizabalaga, A., Rios-Garaizar, J., 2012. The First Human Occupation of the Basque Crossroads. Journal of World Prehistory 25(3-4), 157-181.

Arruabarrena, J., Mujika, J.A., Sasieta, M., 2007 Cueva de Astigarraga (Deba). Arkeoikuska 2006, 179-181. 
Bagolini, B., 1968. Richerche sulle dimensioni dei manuffati litici preistorici non ritoccati. Annali dell'Universitá de Ferrara 10, 195-218.

Baldeón, A., 1974. El yacimiento del Paleolítico Inferior de Murba. Estudios de Arqueología Alavesa 6, 17-46.

Baldeón, A., 1978a. Estudio de un Hachereau aparecido en Peñacerrada (Alava). Estudios de Arqueología Alavesa 9, 11-16.

Baldeón, A., 1978b. Contribución al estudio de yacimientos pospaleolíticos al aire libre. (Álava). Landa y Saldarroa. Estudios de Arqueología Alavesa 9, 17-45.

Baldeón, A., 1993. El yacimiento de Lezetxiki (Gipuzkoa, País Vasco). Los niveles musterienses. Munibe Antropologia-Arkeologia 45, 3-97.

Baldeón, A., Murga, F., 1989. Útiles Paleolíticos en una gravera del Río Zadorra, afluente del Ebro, Álava. Kobie Paleantropología 18, 113-122.

Barandiarán, I., Montes, L., 1991-1992. Ocupaciones del Paleolítico en Urbasa (Navarra), el sitio de Mugarduia Norte. Trabajos de Arqueología Navarra 10, 21-67.

Barandiarán, I., 1967. El Paleomesolítico del Pirineo Occidental. Bases para la sistematización tipológica del instrumental óseo paleolítico. Monografías Arqueológicas III. Universidad de Zaragoza, Zaragoza.

Barandiarán, I., Vallespí, E., 1984. Prehistoria de Navarra. Trabajos de Arqueología Navarra 2, p. 260.

Barandiarán, J.M., 1950. La industria prehistórica de la región inferior del Nive. Eusko Jakintza IV, 13. Bayona. 1953 El hombre prehistórico en el País Vasco. Editorial Vasca Ekin, Buenos Aires.

Barandiarán-Irizar, L., 1989. Cartas a José Miguel de Barandiarán (primera etapa 1915-1936). Caja de Ahorros Municipal de San Sebastián, San Sebastián.

Beguiristáin, M.A., 1974. La colección Barandiarán de Coscobilo, de Olazagutía (Contribución al estudio de la industria lítica del yacimiento). Príncipe de Viana 136-137, 345-401.

Beguiristáin, M.A., 1989. Dos nuevos bifaces de tipología achelense en Tierra Estella (Navarra). In: XIX Congreso Nacional de Arqueología, Zaragoza, 37-48.

Beguiristáin, M.A., 1995. Primeros habitantes de Navarra, los cazadores-recolectores del Paleolítico Inferior. Cuadernos de Arqueología de la Universidad de Navarra 3, 33-52.

Beguiristáin, M.A., 2000 Paleolítico medio en Navarra, nuevos datos para una síntesis. SPAL 9, 209-224.

Beguiristáin, M.A., Labeaga, J.C., 1993. Pieza de tipología abbevillense procedente del término de Viana (Navarra). Cuadernos de Arqueología de la Universidad de Navarra 1, 9-16.

Beorlegi Ereña, M., 2005. Hallázgos de industria lítica del Paleolítico antiguo en Ilarduia (Álava). Estudios de Arqueología Alavesa 22, 37-50.

Chauchat, C., 1994. La station préhistorique de plein air de Lestaulan, quartier de Maignon, à Bayonne (Pyrénées Atlantiques). Munibe Antropologia-Arkeologia 46, 3-22.

Clarck, G., 1969. World Prehistoric in new perspective. Cambridge.

Fernández Eraso, J., 1989. Los residuos de tecnología lítica del yacimiento de Zatoya. In: Barandiaran, I., Cava, A., El yacimiento prehistórico de Zatoya (Navarra). Trabajos de Arqueología Navarra 8, 138-179.
Fernández Eraso, J., 2005. Los productos brutos de talla. In: Alday, A. (Dir.). El campamento prehistórico de Mendandia. Ocupaciones mesolíticas y neolíticas, 237-283, Fundación Barandiarán, Vitoria-Gasteiz.

Fernández Eraso, J., 2006. Artefactos inéditos del Paleolítico Antiguo hallados en el territorio de Álava. Cuadernos de Arqueología Universidad de Navarra 14, 39-57.

Fernández Eraso, J., Sáenz De Buruaga, A., Urigoitia, T., 1995. Contextualización cultural del conjunto industrial achelense del embalse de Urrúnaga (Álava) en el marco del País Vasco peninsular. Trabalhos de antropologia e etnología 35.

Fernández Eraso, J., Tarriño, A., Eguíluz, L., 2003. Nuevos instrumentos pulimentados procedentes de conjuntos de superficie en el territorio de Álava. Estudios de Arqueología Alavesa 20, 10-41.

Fernández Eraso, J., Larreina, D., Tarriño, A., 2004. El conjunto lítico de superficie de Itsetsasi en el embalse de Urrúnaga (Álava). Estudios de Arqueología Alavesa 21, 17-66.

Fernández Eraso, J., Larreina, D., Tarriño, A., 2005. El conjunto lítico de Tribitu en el embalse de Urrúnaga (Álava). Estudios de Arqueología Alavesa 22, 69-122.

Fernández Eraso, J., García Rojas, M., Larreina, D., Alonso, M., 2012. Las industrias líticas de Echabarri en el embalse de Urrúnaga (Álava). Kobie Paleantropología 31, 73-104.

Fernández Eraso, J., García Rojas, M., 2013. Tipología Analítica. In: García Díez, M., Zapata Peña, L. (Coords.), Métodos y técnicas de análisis y estudio en arqueología prehistórica: de lo técnico a la reconstrucción de los grupos humanos, 479-497.

García Gazólaz, J., 1994. Los primeros depredadores en Navarra: estado de la cuestión y nuevas aportaciones. Cuadernos de Arqueología de la Universidad de Navarra 2, 7-47.

García Rojas, M., 2010. Propuesta de descripción y definición de los productos de debitado desde la Tipología Analítica. Zephyyrus 66(2), 93-107.

IGME 1991a Mapa Geológico de España Escala 1:50000, Elorrio, 87. MAGNA.

IGME 1991b Mapa Geológico de España Escala 1:50000, Vitoria, 112. MAGNA.

Iriarte-Chiapusso, M.J., 2003. Yacimiento de Artazu II (Arrasate, Gipuzkoa). Arkeoikuska 2002, 483-485.

Irigaray, S., 1992. Estudio del yacimiento de Matamala (Viana): los materiales paleolíticos y la industria holocena. II Congreso General de Historia de Navarra. Principe de Viana anejo 14, 75-86.

Laplace, G., 1987. Un exemple de nouvelle écriture de la grille typologique. Dialektikê: Cahiers de Typologie Analytique 19851987, 16-21.

Marcos Pous, A., Mensua, S., 1959. Un hallazgo lítico del Paleolítico Inferior del término de Lumbier (Navarra). Príncipe de Viana 20, 217-225.

Merino-Sanchez, J.M., 1986. Yacimiento de Cabo Higuer en el monte Jaizkibel (Fuenterrabía). Munibe Antropologia-Arkeologia 38, 61-94.

Montes, L., 1988. El Musteriense en la Cuenca del Ebro. Universidad, Departamento de Ciencias de la Antigüedad, Zaragoza. Monografías Arqueológicas 28, p. 326.

Obermaier, H., 1925. El hombre fósil. Museo Nacional de Ciencias Naturales, Madrid. 21 ed.

Olarte, I., 2002. Deba-Errezil. Arkeoikuska 2001, 150-151. 
Ormazabal, A., Pastor, B., Urigoitia, T., 1994. Ensayo de estudio analítico del instrumental lítico pulimentado. Su aplicación al conjunto superficial de Urrúnaga (Álava). Munibe Antropología-Arkeologia 46, 87-110

Passemard, E., 1924. Les Stations Paléolithiques du Pays Basque et leurs rela- tions avec les Terrasses d'Alluvions de la Nive, Bayona.

Rios-Garaizar, J., 2013. Industria lítica de los niveles del Paleolítico Medio Antiguo y Paleolítico Superior de Arlanpe (Lemoa, Bizkaia). In: Rios-Garaizar, J., Garate Maidagan, D., Gómez-Olivancia, A. (Eds.), La Cueva de Arlanpe (Lemoa): Ocupaciones humanas desde el Paleolítico medio antiguo hasta la Prehistoria reciente, 177-253, Diputación Foral de Bizkaia, Bilbao. Kobie Serie BAI 3.

Rios-Garaizar, J., Garate Maidagan, D., Iriarte Aviles, E., Cearreta Bilbao, A., Iriarte-Chiapusso, M.J., 2010. Los yacimientos de Mendieta I y II (Sopelana, Bizkaia): Dos ocupaciones al aire libre del Paleolítico inferior y medio. Kobie Paleoantropología 29, 7-18.

Rios-Garaizar, J., Garate, D., Gómez-Olivencia, A., Iriarte-Avilés, E., Aranburu-Artano, A., Arceredillo-Alonso, D., García, A., Iriarte, M.J., Moreno, J., Murelaga, X., Ortiz, J.E., Torres, T., San Pedro, Z., Zapata-Peña, L., 2011. The Lower to Middle Palaeolithic transition in northern Iberia: new data from Arlanpe Cave. Antiquity 85 (329)

Rios-Garaizar, J., Libano Silvente, I., Garate Maidagan, D., 2012. Nuevas localizaciones del Paleolítico Inferior en Uribe Kosta (Bizkaia): Los yacimientos de Moreaga (Sopelana) y Errementariena (Barrika). Kobie Paleoantropología 31, 45-56.

Rios-Garaizar, J., Libano Silvente, I., Garate Maidagan, D., Gómez-Olivencia, A., Regalado Bueno, E., 2013. Nuevas localizaciones arqueológicas al aire libre del Paleolítico Inferior y Medio en las cuencas del Gobela y del Udondo (Bizkaia). Kobie Paleoantropología 32, 39-60.

Rios-Garaizar, J., Garate Maidagan, D., Gómez-Olivencia, A., Iriarte, E., Arceredillo-Alonso, D., Iriarte-Chiapusso, M.J., Garcia-lbaibarriaga, N., García-Moreno, A., Gutierrez-Zugasti, I., Torres, T., Aramburu, A., Arriolabengoa, M., Bailón, S., Murelaga, X., Ordiales, A., Ortiz, J. E., Rofes, J. y San Pedro, Z., 2015. Short-term Neandertal occupations in the late Middle Pleistocene of Arlanpe (Lemoa, northern Iberian Peninsula). Comptes Rendus Palevol 14 (3), 233-244.

Sáenz de Buruaga, A., Urigoitia, T., 1986. Evidencias aisladas de cantos tallados en las márgenes del embalse de Urrúnaga (Álava). Estudios de Arqueología Alavesa 13, 29-45.
Sáenz de Buruaga, A., Urigoitia, T., Fernández Eraso, J., 19881989. El conjunto industrial achelense del embalse de Urrúnaga (Álava). Zephyrus 41-42, 27-54.

Sáenz de Buruaga, A., Urigoitia, T., Fernández Eraso, J., 1992. Datos preliminares sobre el conjunto de cantos tallados descubierto en el embalse de Urrúnaga (Álava). In: Cearreta, A., Ugarte, F., The Late Quaternary in the Western Pyrenean Region, 405-413. Universidad del País Vasco, Bilbao.

Sáenz de Buruaga, J.A., Urigooitia, T., Madinabaitia, J.A., 1994. Nuevos indicios industriales en cuarcita del Paleolítico Antiguo en Álava. Veleia 11, 23-33.

Sánchez, A., 2012. El Hábitat al aire libre en el Occidente Alavés. El caso de Zabalain en el embalse de Urrúnaga (Álava). CKQ Estudios de Cuaternario/Kuaternario Ikasketak/Quaternary Studies 2, 159-184.

Sánchez, A., Calvo, A., Fernández Eraso, J., 2013. El conjunto lítico de superficie de Tribitu I. Una nueva evidencia de ocupación humana en el embalse de Urrúnaga (Álava) durante la Prehistoria. Kobie Paleantropología 32, 61-78.

Tarriño, A., 2006. El sílex en la Cuenca Vasco-Cantábrica y Pirineo navarro: Caracterización y su aprovisionamiento en la Prehistoria. Museo Nacional y Centro de Investigación de Altamira. Monografía 21.

Thibault, C., 1976a. Les civilisations du Paléolithique inférieur dans le Sud Ouest (Pays Basque, Landes, Gironde). In: Lumley, H. (Ed.). La Préhistoire Française I.2. C.N.R.S. París.

Thibault, C., 1976b. Les civilisations du Paléolithique moyen du Sud Ouest (Pays Basque et Béarn, Landes, Gironde). In: Lumley, H. (Ed.). La Préhistoire Française I.2, C.N.R.S, París.

Tixier, J., 1956. Le Hachereau dans l'Acheuléen nord-Africain. Notes Typologiques. In: Congrès prehistorique de la France, XV sesión, 914-923. Poitiers-Angoulême.

Utrilla, P., 1984. El Paleolítico en el curso medio del río Ebro: Calahorra y su entorno. Bimilenario de su Fundación, Madrid.

Vallespí, E., García Serrano, R., 1974. Bifaz achelense de Estella. Cuadernos de Trabajos de Historia 2, Prospecciones Arqueológicas en Navarra 1, 10-20. 


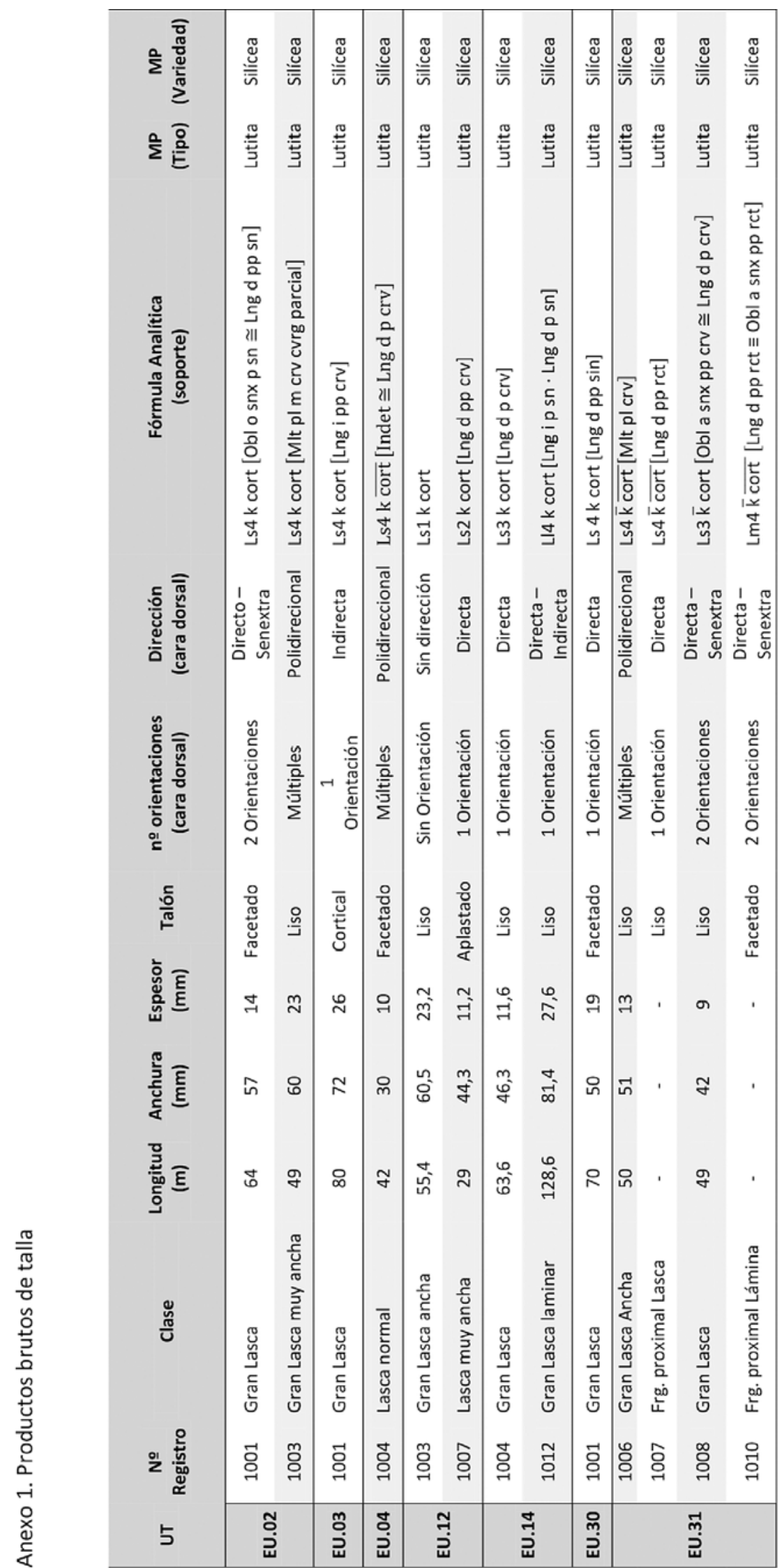




\begin{tabular}{|c|c|c|c|c|c|c|c|c|c|c|c|c|c|c|c|c|}
\hline 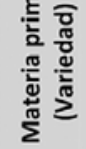 & 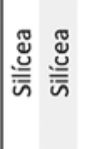 & 茳 & 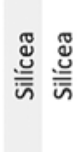 & 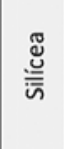 & 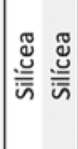 & 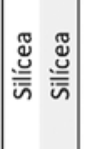 & 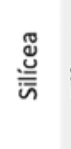 & 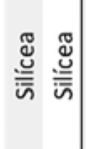 & 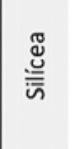 & 芯 & 㤩 & 总 & 兽 & 胥 & 苞 & 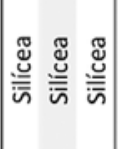 \\
\hline 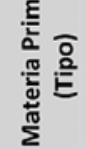 & $\stackrel{\frac{\pi}{5}}{3}$ & $\stackrel{\frac{5}{5}}{\Xi}$ & $\stackrel{5}{5}$ & $\stackrel{5}{\Xi}$ & 苞营 & 营 & $\stackrel{\frac{\pi}{5}}{3}$ & $\begin{array}{ll}\frac{\pi}{5} \\
\stackrel{5}{3} \\
\end{array}$ & Еّ & $\stackrel{\Xi}{\Xi}$ & $\stackrel{\mathbb{5}}{3}$ & 营 & 苞莺 & $\stackrel{5}{5}$ & E) & 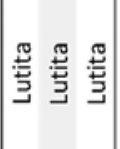 \\
\hline$\frac{\bar{\Xi}}{4}$ & $\bar{n} \bar{s}$ & $i \bar{s}$ & in $\frac{0}{2}$ & $\stackrel{\circ}{2}$ & in $\frac{0}{2}$ & $\frac{0}{2}$ i & $\bar{n}$ & $\bar{n} \bar{i}$ & 운 & $\tilde{\bar{n}}$ & 운 & $\tilde{\text { ஸे }}$ & 울 운 & in & 20 & $i \bar{x} \frac{0}{2}$ is \\
\hline : & $\bar{n} \bar{n}$ & $\bar{n}$ & $\bar{n}$ is & $\bar{n}$ & is is & in $\bar{n}$ & $\bar{n}$ & $\bar{n} \bar{n}$ & in & $\bar{n}$ & $\bar{n}$ & 2 & in $\stackrel{0}{2}$ & is & $\bar{n}$ ति & $\bar{n} \frac{1}{2} \bar{s}$ \\
\hline 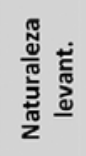 & 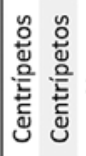 & 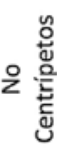 & 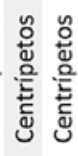 & そ) & 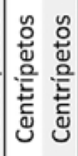 & 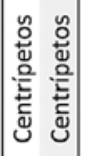 & そ) & 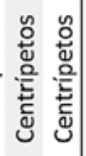 & そ) & そ) & そ) & 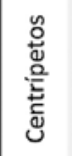 & 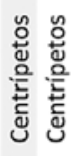 & 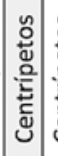 & 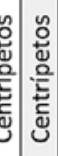 & 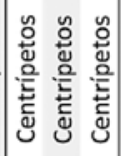 \\
\hline 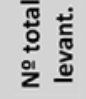 & $\rightarrow \exists$ & 0 & $\approx \infty$ & $\circ$ & $\pi \stackrel{m}{9}$ & $A$ in & $n$ & $\exists m$ & J & न & 요 & $\stackrel{L}{N}$ & ஜ & & ค & NA \\
\hline 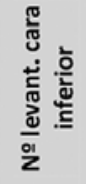 & 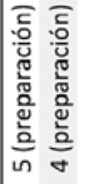 & 0 & 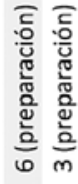 & $\circ$ & 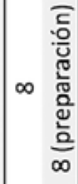 & 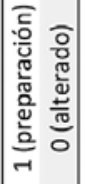 & 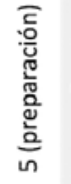 & in 0 & 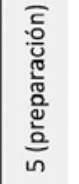 & 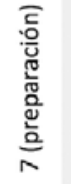 & $m$ & 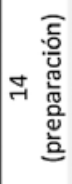 & 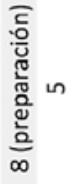 & 0 & 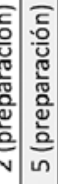 & 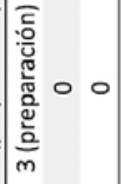 \\
\hline 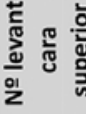 & $\infty$ 욱 & $\circ$ & 0 in & $\circ$ & I in & $\begin{array}{lll}0 & \text { in }\end{array}$ & $N$ & $0 N$ & $\sigma$ & 욱 & $n$ & $\approx$ & 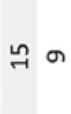 & 윽 & $\checkmark$ 의 & $\nabla r-$ \\
\hline 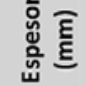 & $\tilde{\text { ก }}$ & q & $\stackrel{\infty}{\infty}$ ల్ల & 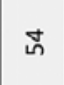 & $\stackrel{m}{*} \stackrel{2}{2}$ & 迤 望 & $\sigma$ & 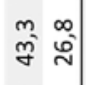 & ì & : & 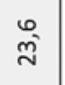 & $\stackrel{0}{-1}$ & जे & $\stackrel{\circ}{~}$ & $n$ & $m \stackrel{m}{\sim} \approx$ \\
\hline 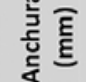 & 0 & $\overrightarrow{6}$ & $\infty$ & I & 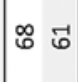 & $ং \$$ & $\tilde{\infty}$ & 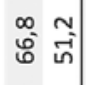 & $\vec{i}$ & 告 & นี้ & $\stackrel{m}{\stackrel{n}{2}}$ & \begin{tabular}{l}
0 \\
\multirow{\sigma}{*}{$\tilde{G}$}
\end{tabular} & 5 & (5) & 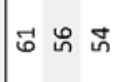 \\
\hline $\bar{E}$ & $\vec{\infty} \vec{\sigma}$ & 8 & ర్త & $\infty$ & $\infty$ & ஜ & $\underset{\widetilde{N}}{\stackrel{్}{*}}$ & 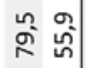 & 每 & 8 & 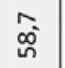 & $\begin{array}{l}\text { के } \\
\text { वे }\end{array}$ & ก ริ สิ & I & 2 & $\infty$ ऽ \\
\hline 竞 & 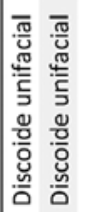 & 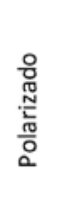 & 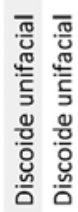 & 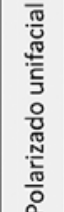 & 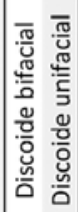 & 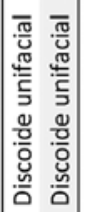 & 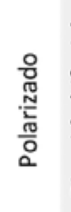 & 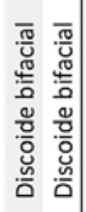 & 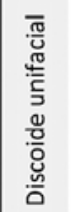 & 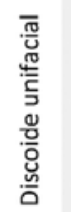 & 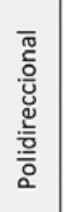 & 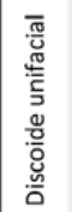 & 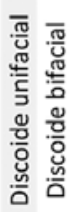 & 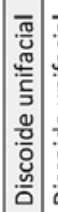 & 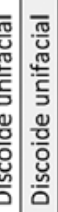 & 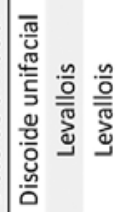 \\
\hline 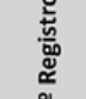 & ర్ష ర్త & ర్తి & ఫ్త & ర్ల & ర్త ర్త & ర్తి & 苛 & ర్ ర్తి ర్తు & ర్తే & ర్తి & ర్తు & ठี & ర్తి స్త & 官 & t) & ర్తి ర్త ర్త \\
\hline & & i⿱ & & סั & ț & & & 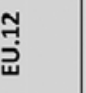 & & $\stackrel{m}{\stackrel{m}{3}}$ & & $\overline{\bar{u}}$ & & : & ș & ì \\
\hline
\end{tabular}




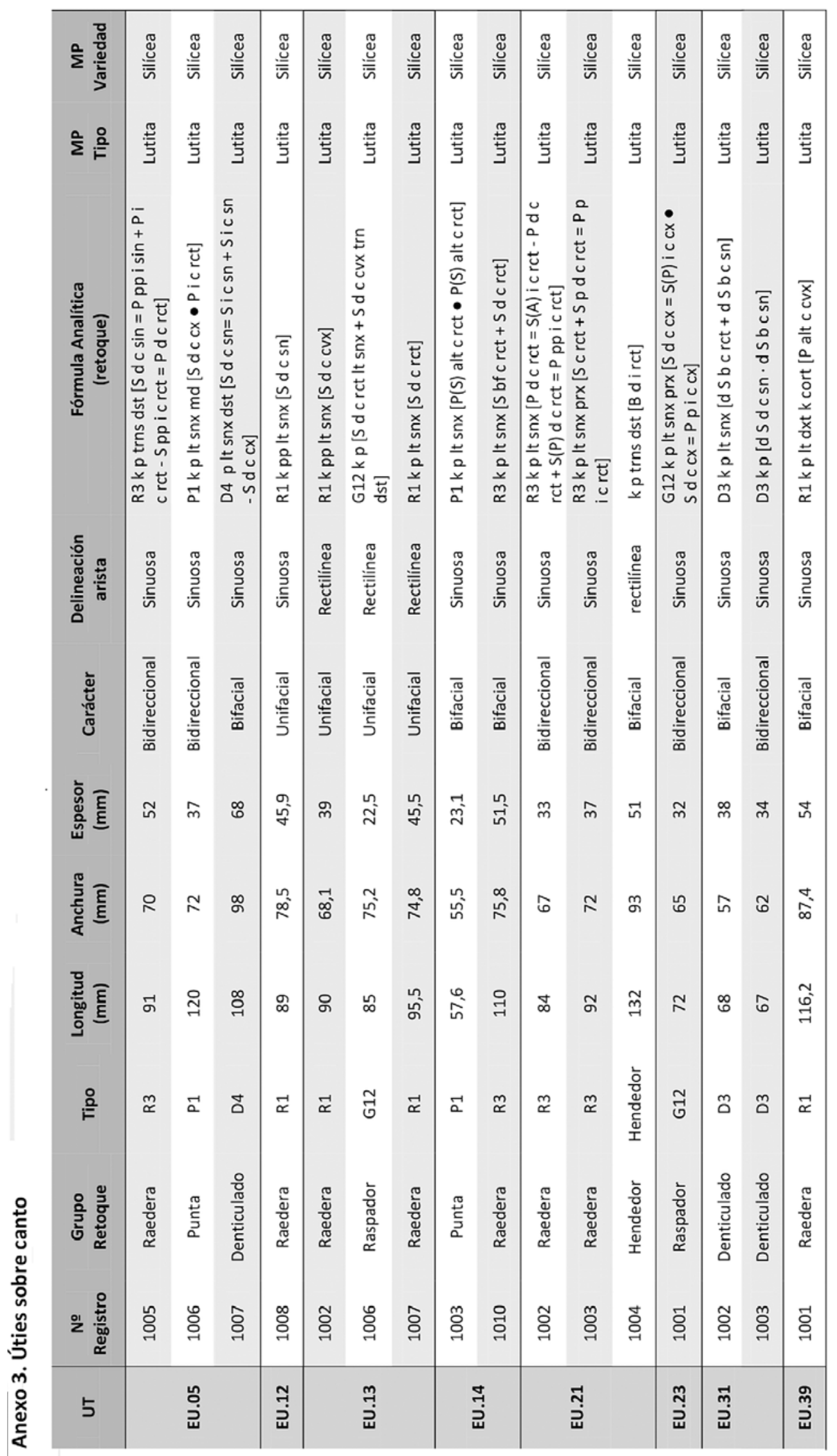




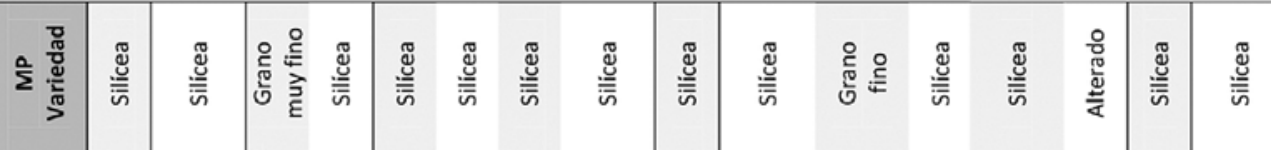

言永

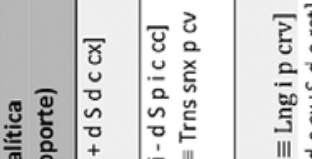

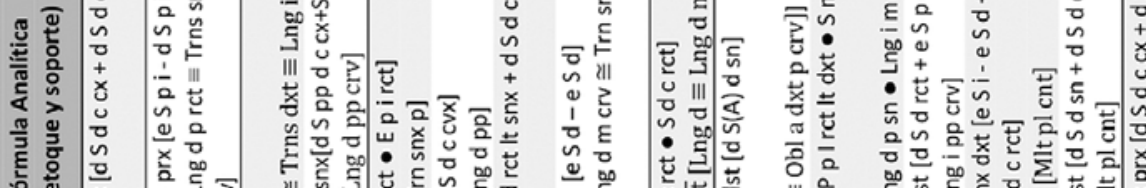

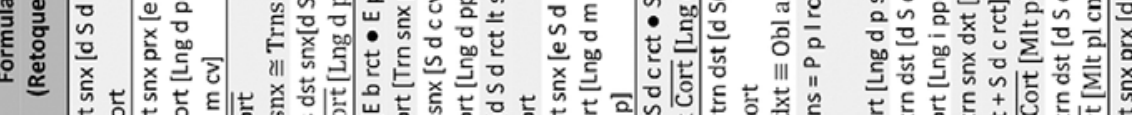

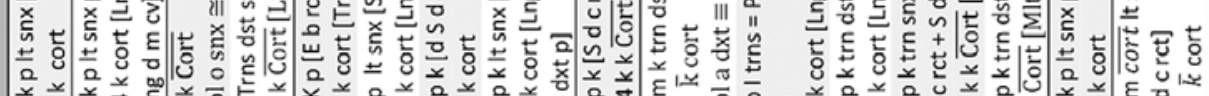

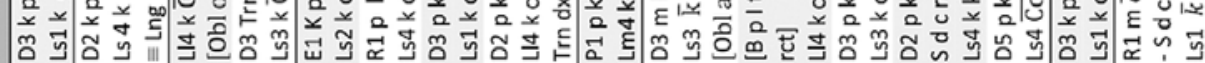

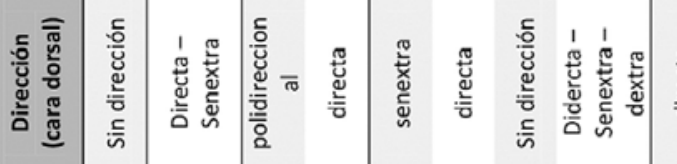

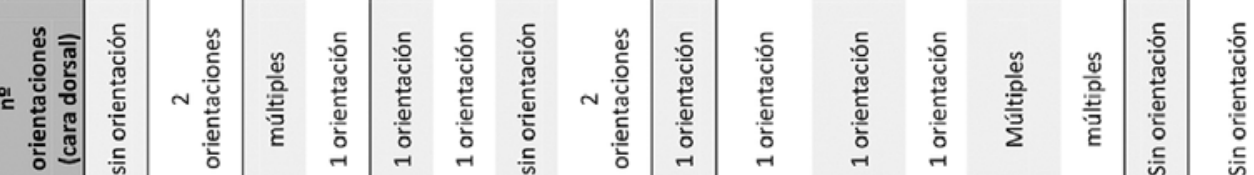

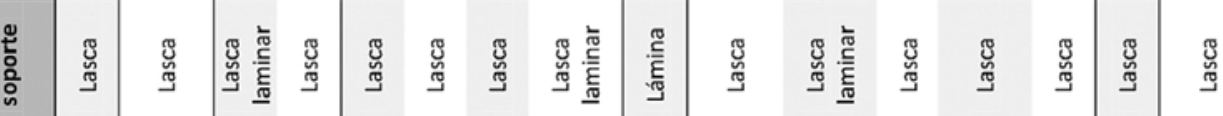

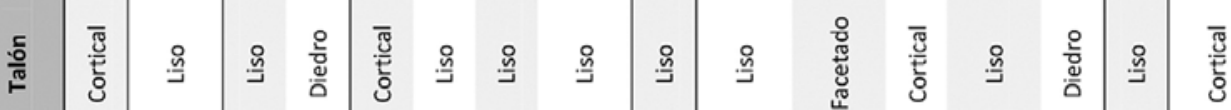

造高

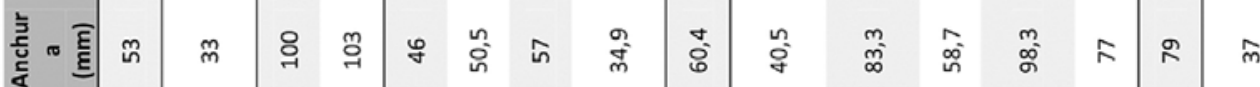

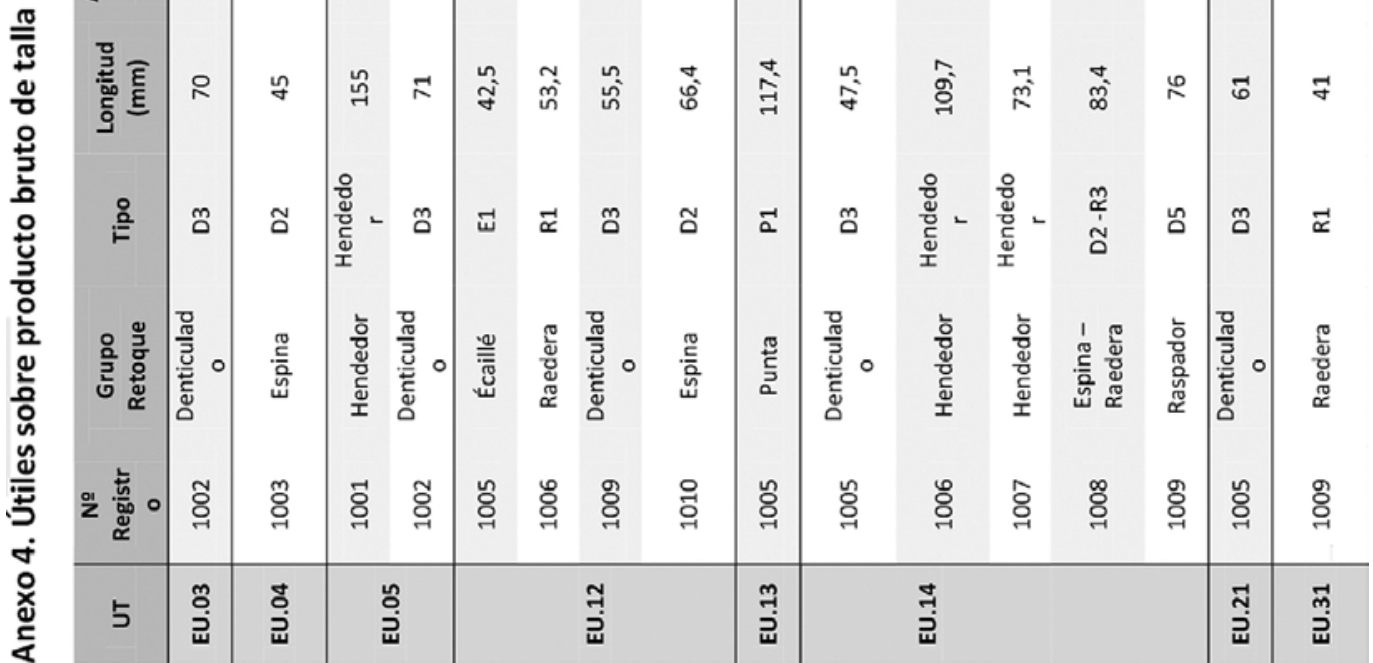


